\title{
CONTRATOS DE INVESTIGACIÓN \\ Y DESARROLLO CONJUNTO
}

KAROLL JULIANA RAMÍREZ-VELASCO*

\section{RESUMEN}

Actualmente la investigación conjunta es una de las formas más utilizadas para producir y transferir conocimiento. Dicha modalidad implica que por medio de un contrato de investigación y desarrollo $(\mathrm{I}+\mathrm{D})$ dos o más individuos unan esfuerzos para investigar o desarrollar una tecnología. Así las cosas, el objetivo de este artículo es analizar la naturaleza jurídica de estos contratos e identificar las características, las clases, las obligaciones y las etapas contractuales de ellos.

Palabras clave: R\&D; transferencia de tecnología; contratos; propiedad intelectual; investigación conjunta; innovación; cooperación.

\section{RESEARCH AND DEVELOPMENT CONTRACTS}

\section{ABSTRACT}

Joint research is currently one of the most used and important ways to produce and share knowledge. This type of investigation is generally made through a contract called research and development agreement (R\&D) in which two or more individuals combine efforts to create or develop a technology. Therefore, the objective of this paper is to identify the nature, obligations, and characteristics of R\&D contracts.

Keywords: R\&D, technology transfer, contracts, intellectual propriety, joint research, innovation, cooperation.

\footnotetext{
* Abogada de la Universidad Externado de Colombia (Bogotá). Contacto: julianarave@hotmail. com. Fecha de recepción: 24 de febrero de 2020. Fecha de aceptación: 4 de abril de 2020. Para citar el artículo: Ramírez-Velasco, Karoll Juliana. Contratos de investigación y desarrollo conjunto. Revista La Propiedad Inmaterial n. ${ }^{\circ}$ 29, Universidad Externado de Colombia, enerojunio, 2020, pp. 183-214. DoI: https://doi.org/10.18601/16571959.n29.07.
} 


\section{INTRODUCCIÓN}

Actualmente la tecnología desempeña una función clave en el desarrollo económico $^{1}$. La adopción de nuevas técnicas, la creación de nuevo conocimiento y el perfeccionamiento del capital humano por medio de la capacitación ha mejorado los índices de crecimiento e incrementado la productividad de los individuos y las compañías a escala mundial ${ }^{2}$. Así mismo, la intensidad con que las nuevas tecnologías se desarrollan y quedan velozmente obsoletas ha alterado profundamente el proceso de generación y adquisición de conocimientos ${ }^{3}$, y se requiere un constante esfuerzo para la actualización de la técnica y la información disponible ${ }^{4}$.

Sin embargo, son pocos los países que logran desarrollar procesos de innovación y producción tecnológica a gran escala o de forma masiva ${ }^{5}$. Lo anterior se debe, principalmente, al alto costo que tienen los procesos de investigación, desarrollo y producción de ciencia e innovación ${ }^{6}$, lo cual tiene como consecuencia que solamente aquellos sujetos o países con una gran capacidad económica puedan invertir y crear conocimiento ${ }^{7}$. De esta manera, se genera una brecha en la que, por un

1 Pece, Andreea, Oliviera, Simona y Salisteanu, Florina. Innovation and Economic Growth: An Empirical Analysis for Cee Countries. En: Procedia Economics and Finance, 2015, vol. 12, p. 462. "The connection between economic growth and innovation presents a great interest for researchers, as a result, the concept is a well debated topic in the financial literature."

2 Banco Internacional de Reconstrucción y Fomento, y Banco Mundial. Informe sobre el crecimiento. Estrategias para el crecimiento sostenido y el desarrollo incluyente. 2008, p. 36. "El progreso tecnológico marca la diferencia entre las economías en desarrollo que crecen aceleradamente y las que lo hacen a un ritmo lento. La principal diferencia entre las regiones cuyo producto interno bruto (PIB) per cápita viene creciendo a ritmo acelerado desde principios de los años noventa (Asia oriental, Asia meridional y los países en desarrollo de Europa) y aquellas cuyo crecimiento ha sido más débil (América Latina, Oriente Medio y África) reside en el ritmo al que avanza la tecnología."

3 Ibíd.

4 Lutteral, Patricio. La transferencia internacional de tecnología desafíos, tratamiento tributario internacional y propuestas para la redacción de contratos. Tesis de Maestría en Comercio Internacional. Universitat de Barcelona, 2016, p. 6-11.

5 Ibíd. “[...] De hecho, la producción tecnológica no es homogénea en todos los países. Un estudio realizado por J Sach mostraba en el año 2000 la nueva división del mundo está fundamentada en el nivel de desarrollo tecnológico de los países. Esta división es cada vez más profunda: solamente un $15 \%$ de la población mundial provee la mayor parte de las innovaciones, mientras que menos de la población mundial es capaz de adaptar tecnologías extranjeras o iniciar procesos de innovación propios."

6 Guerrero Gaitán, Manuel. Los contratos de transferencia internacional de tecnología América Latina, Estados Unidos y la Unión Europea. Bogotá: Universidad Externado de Colombia, 2014, p. 33. "La combinación de los altos costes asociados a la investigación y el desarrollo, junto con la protección de los resultados, de estas actividades conducen a que en la mayoría de los casos, los titulares de los derechos de propiedad intelectual sean empresas con un importante poder económico, bien sea porque han desarrollado su propia tecnología o porque han adquirido los derechos contractualmente."

7 Banco Internacional de Reconstrucción y Fomento, y Banco Mundial. Op. cit., p. 36. "No es de sorprender que los países ricos utilicen la tecnología más ampliamente que los países pobres, en parte porque pueden costearla y también porque un mayor número de sus ciudadanos y empresas tienen los conocimientos necesarios para usarla. ¿En qué se diferencian los países con buen desempeño en materia tecnológica? En un determinado nivel de ingresos, la diferencia reside en el grado al que se aprovechan las tecnologías más antiguas en vez de las más recientes." 
lado, se encuentran los países y empresas con recursos económicos, líderes en el desarrollo de procesos de innovación y producción de tecnología, y, por otro, los que no cuentan con los recursos suficientes para desarrollar procesos autónomos de innovación y producción de tecnología ${ }^{8}$, quienes dependen en gran medida de los avances tecnológicos hechos por aquellos países y empresas que si los pueden costear.

La principal forma de superar esta brecha es a través del intercambio de saberes e innovación que se da en el marco de un mercado globalizado, más específicamente a través de lo que se conoce como" "procesos de transferencia de tecnología" ${ }^{9}$, en los cuales los países desarrollados o empresas productoras de tecnología por medio de contratos atípicos e innominados, y otros mecanismos, comparten conocimiento con los países en vías de desarrollo o empresas receptoras, de modo que para estos últimos significa el acceso a tecnología sin necesidad de invertir importantes sumas de dinero en investigación y desarrollo ${ }^{11}$.

Uno de los contratos más utilizados para producir y transferir tecnología es el contrato de investigación y desarrollo (en adelante, $\mathrm{I}+\mathrm{D})^{12}$, una figura gracias a la cual, en primer lugar, ha sido posible llevar a cabo proyectos de innovación que en un pasado eran imposibles de lograr ${ }^{13}$, esto debido a que este acuerdo permite una colaboración flexible y sin precedentes entre todo tipo de sujetos que generan conocimiento, es decir, particulares, universidades y Estado. Y, en segundo lugar, ha permitido que grandes compañías se alíen para realizar investigaciones conjuntas, lo cual las faculta para generar innovación a bajos costos y en un tiempo más corto. Un ejemplo de lo anterior es el caso de Tesla, que en el año 2009 celebró un I+D con Toyota, el cual le permitió no solo tener acceso y desarrollar tecnología de punta $^{14}$ sino también solventar su situación económica.

8 Jaime Álvarez Soberanis. Transferencia internacional de la tecnología y el diálogo nortesur. Revista Jurídica. Tomo i. México. 1981, p. 188. "La dependencia de los países en vías de desarrollo es considerablemente mayor y la contribución de la tecnología adquirida es más baja que para otros países importadores netos de tecnología porque los países en vías de desarrollo no tienen, en la mayor parte de los casos, la capacidad de organización, de investigación y de ingeniería para poder ajustar, adaptar la tecnología a sus propias necesidades."

9 Guerrero Gaitán, Manuel. Los contratos de transferencia internacional de tecnología América Latina, Estados Unidos y la Unión Europea. Op. cit., p. 35. "[...] precisamente en los países menos desarrollados son donde se utilizan este tipo de acuerdos como motor del desarrollo $[\ldots]$ ".

10 Para ver la definición de transferencia de tecnología consultar: Guerrero Gaitán, Manuel. Tipología de los contratos de transferencia de tecnología (en línea). En: Revista La Propiedad Inmaterial, n.o 13, 2009 (consultado el 14 de junio del 2020). Disponible en: https://revistas.uexternado.edu.co/index.php/propin/article/view/461.

11 Guerrero Gaitán, Manuel. Los contratos de transferencia internacional de tecnología América Latina, Estados Unidos y la Unión Europea. Op. cit., p. 35.

12 En español se conocen como "acuerdos de investigación y desarrollo (I+D)".

13 wipo (sitio virtual) Intellectual Property and R\&D: A Path to Success (consultado el 14 de junio de 2020). Disponible en: https://www.wipo.int/ipadvantage/en/details.jsp?id=2559. "Tal es el caso de FK Biotecnología S.A. (FКB), un grupo de inversionistas quienes utilizando los acuerdos de R\&D se unieron con el departamento de ciencia y tecnología del estado de la universidad de Rio Grande de Brasil para realizar una investigación que ha sido considerada por la wipo pionera y exitosa en el campo de la biotecnología. Dicha investigación consiste en producción de vacunas para el cáncer."

14 Hoang, H. A., Rothaermel. How to manage alliences strategically (en línea) mit Sloan 
La relevancia de los contratos I+D es tan alta que la Unesco ha señalado que esta figura es clave para el desarrollo tecnológico y que se deben fomentar las operaciones de $\mathrm{I}+\mathrm{D}$ con el fin de cumplir con los Objetivos de Desarrollo Sostenible (ODS) del 2030. Como consecuencia de lo anterior, los países se han comprometido en aumentar considerablemente hasta 2030 el gasto público y privado en I+D y el número de investigadores ${ }^{15}$.

Teniendo en cuenta la importancia de los contratos I+D en la actualidad, el objetivo de este documento es describir y analizar la naturaleza jurídica de este tipo de contrato, para lo cual el presente trabajo se dividirá en cuatro partes. En la primera se definirá el I+D; en la segunda parte se detallará el contenido del contrato; en la tercera parte se presentarán las clasificaciones de dichos contratos; finalmente, en la cuarta parte se describirá la manera en que se estructuran estos acuerdos.

Por último, es menester mencionar que para elaborar el análisis jurídico que se pretende realizar en este escrito se utilizarán como fuente de conocimiento textos jurídicos y económicos ya que, en primer lugar, para un estudio profundo del tema es necesario comprender estas dos ópticas, y en segundo lugar, debido a que el I+D ha sido abordado en su mayoría desde la economía.

\section{DEFINICIÓN}

I+D es un término de origen anglosajón que comenzó a ser utilizado en los años sesenta por los economistas ${ }^{16}$, quienes con el estudio de este concepto buscaban describir e investigar el fenómeno de la colaboración e inversión conjunta de individuos que pretendían desarrollar proyectos de desarrollo tecnológico e innovación. Al principio, el estudio del I+D se centró en la recolección, medición y cuantificación de datos dirigidos a identificar mejor la figura desde una perspectiva netamente económica ${ }^{17}$. Esto debido a que la principal motivación de los académicos para estudiar dicho fenómeno era comprender el papel central que desempeñaban la tecnología y la

Management Review. 2016 (agosto 23 del 2016) (consultado: 15 de junio del 2020). Disponible en: https://sloanreview.mit.edu/article/how-to-manage-alliances-strategically/ "Tesla, which began selling its all-electric Roadster model in 2008, had neither a market nor legitimacy. More-over, it was plagued with both thorny technical problems and cost overruns. Yet it managed to overcome these early challenges, in part by turning prospective rivals into alliance partners. In 2009, Tesla worked out the alliance (R\&D) [...] The deal provided Tesla with access to superior engi-eering expertise and a cash infusion of $\$ 50$ million, helping to save the company from potential bankruptcy. The alliance with Toyota, signed the following year, brought other benefits. It enabled Tesla to buy the former New United Motor Manufacturing, Inc".

15 Unesco Institute for Statistics (sitio virtual). How much does your country invest in $\mathrm{R} \& \mathrm{D}$ (consultado el 15 de junio del 2020). Disponible en: http://uis.unesco.org/apps/visualisations/research-and-development-spending/.

16 Casanova Navarro, Mariano. Proyectos de i+d e innovación en universidades: Determinación de su carácter empresarial (en línea). Tesis doctoral. Universidad politécnica de valencia. 2016, p. 22 (consultado: 14 de junio del 2020). Disponible en: iunet.upv.es/handle/10251/60155. "[...] No fue sino hasta la década de los sesenta en la que se comenzó un verdadero análisis sistemático del término R\&D.”

17 Griliches zVI. R\&D, Patents, and Productivity. En: National Bureau of Economic Research. London. University of Chicago Press, 1984, vol. I, p:1-21.isBn: 0-226-30884-7. 
innovación en el crecimiento de la economía. A partir de la década de los ochenta ${ }^{18}$, dado el incremento exponencial de I+D, este comenzó a ser abordado desde diferentes disciplinas, tales como la historia, la psicología social ${ }^{19}$ y el derecho, lo cual trajo como resultado una amplia y diversa literatura sobre la materia ${ }^{20}$.

Actualmente, pese a que el I+D es cada vez más común e investigado, no existe en la literatura una definición unánime y universal de él, esto debido a que se trata de un concepto de naturaleza compleja que integra múltiples elementos de diversas disciplinas, lo cual hace que las definiciones omnicomprensivas sean difíciles de formular ${ }^{21}$. Para efectos del presente texto, antes de proponer una definición jurídica del I+D, se ha optado por exponer de una manera breve el significado que tiene la figura desde la disciplina de la economía toda vez que, es la principal área del conocimiento que se ha dedicado a la investigación de dicho concepto.

Desde una perspectiva económica se dice que el I+D tiene dos acepciones: la primera de ellas es el I+D como un tipo de acuerdo de cooperación ${ }^{22}$ el cual permite que se presente una alianza estratégica entre dos o más empresas, grupos de investigación, universidades o entes estatales, con el objetivo de que las partes aliadas puedan investigar y producir conocimiento conjunto de una manera eficiente y flexible $^{23}$; la segunda de ellas es el I+D como una inversión realizada en proyectos de innovación y producción de tecnología, ya sean públicos o privados.

\section{A. I+D DESDE UNA PERSPECTIVA JURÍDICA \\ (DEFINICIÓN DEL I+D COMO CONTRATO)}

Desde una óptica jurídica, el acuerdo I+D es un contrato, dado que en esencia es un instrumento utilizado por los individuos para crear y contraer obligaciones. Sin embargo, para abordar el concepto de I+D y la pertenencia de este a la categoría del contrato es necesario dar una definición más precisa de este último concepto. Para ello, se debe tener en cuenta que los I+D pueden ser celebrados por sujetos que provienen del mismo sistema legal o por individuos que pertenecen a diferentes sistemas legales. La última situación señalada implica que diferentes nociones de contrato coincidan en la creación de dichos acuerdos En ese sentido, se procederá a definir el término contrato en los dos principales sistemas legales: sistema del

18 Rajneesh, Narula, Hagedoorn, John. Innovating through strategic alliances: moving towards international partnerships and contractual agreements. En: Technovation, Febrero 1999, vol. 19 , n. ${ }^{\circ}$, p. 283-294.

19 Jaffe, Adam. Technological Opportunity and Spillovers of R\&D: Evidence from Firm's Patents, Profits and Market Value. En: American Economic Review, diciembre 1986, vol. 76, n. ${ }^{\circ}$, p. 984-999.

20 Griliches zVi, R\&D, Patents, and Productivity. Op. cit., p. 1-21.

21 Martínez Noya, Andrea y Narula, Rajneesh. What more can we learn from R\&D alliances? A review and research agenda. En: Business Research Quarterly, marzo 2018, vol. 21, n. ${ }^{\circ}$ 3, p. $195-212$.

22 Ibíd.

23 Ibíd. 
derecho continental y common law, esto con el objetivo analizar la pertenencia de los acuerdos del I+D a la categoría del contrato.

\section{I $+D$ como contrato en el derecho continental}

La noción de contrato en el civil law proviene del derecho romano ${ }^{24}$. Dicho concepto fue desarrollado por juristas como Gayo ${ }^{25}$, Labeon ${ }^{26}$ y Teófilo ${ }^{27}$ entre otros, quienes establecieron que el contrato era fuente de las obligaciones y que este estaba conformado por dos elementos: el primero de ellos era el consenso entre las partes y el segundo consistía en la reciprocidad y el equilibrio que debían existir entre las obligaciones creadas por el contrato ${ }^{28}$.

La modernidad hereda dicha concepción de contrato, y de la mano de la teoría voluntarista ${ }^{29}$ se formula el concepto más aceptado y utilizado ${ }^{30}$ hasta la actualidad, concepto según el cual contrato es ${ }^{31}$ un acuerdo de dos o más personas (o partes) con el fin de generar obligaciones o de crear modificar o extinguir una relación jurídica.

24 Patricio, Javier. Contrato la formación de un concepto. Primera edición, editorial Civitas, 2008, p. 73- 88. ISBN 9788447031528. "El término de contrato tiene su origen en el latín contrahere termino que es usado en las fuentes jurídicas y literarias con significados diversos, se utiliza como sinónimo de commitere (cometer) cuando se habla de contrahere crimen, o de constituere (constituir)."

25 Esborraz, David. La noción de contrato entre "synallagma” y "convetio" en la tradición romanista y sus proyecciones en el sistema jurídico latinoamericano. En: Roma e America. Diritto Romano Comune Rivista di Dirito dell'integrazione e Unificazione del Diritto in Europa e in America Latina, 2008, vol. 26, p. 26. "A Gayo se le atribuye la formulación del consentimiento como elemento aglutinador del contrato, es decir, para Gayo el consentimiento o por lo menos la intención de obligarse es un elemento común de todos los contratos."

26 D. 50. 16. 19 [...] contrato significa obligación de una y de otra parte lo que los griegos llaman synallagma como la compra, venta, locación, conducción y sociedad gestionado significa cosa hecha con palabras.

27 Patricio, Javier. Op. cit., p. 73- 88. "Fue Teófilo (s. vi d. C.) quien participó en la Codificación de Justiniano, el comentarista que realizó una interpretación sintetizadora de todo el material conservado de la institución del contrato. Así, en su Paráfrasis a las Instituciones de Justiniano, definió contrato como “...el acuerdo y el consentimiento de dos o más sobre la misma cosa (sobre el mismo conjunto de intereses), dirigido a crear una obligación, y a quedar el uno obligado hacia el otro"

28 Ibíd. "Para Labeón, el acento estaba en la reciprocidad de las obligaciones, cuestión que también era importante para la corriente consensualita de la "escuela sabiniana/muciana" y para todos los comentaristas que tomaron estas opiniones como punto de partida. Por ejemplo, Gayo limitaba los alcances de la voluntad al indicar que las partes quedaban recíprocamente obligadas al cumplimiento de los límites del "principio de la correlatividad" (Gai. 3, 137). Y como vimos, Teófilo tampoco escapa de la presencia del carácter recíproco de las obligaciones generadas por la convención.”

29 Bianca Massimo. Derecho Civil ir. El contrato. Primera edición, Colombia, Universidad Externado de Colombia. 2000. Tomo 3, p. 45. ISBN 978-958-710-192-8. “Teoría elaborada por la pandectística del siglo xix sobre la base del derecho común, esta ve la esencia del contrato en la voluntad creadora del sujeto, una declaración desprovista de voluntad seria, entonces inidónea para formar el contrato. Dicha voluntad debe ser expresada y de igual manera debe corresponder con la voluntad real del sujeto."

30 Ibíd. "No siendo esta la única teoría, también existe una teoría que opta por una visión más objetiva, esta teoría es conocida como la teoría preceptiva la cual resalta el papel del acuerdo de voluntades. Sin embargo, se puede hablar de contrato si además de existir un acuerdo de voluntades el contrato se traduce en un hecho social."

31 Ibíd. "También definido según Bianca, desde una perspectiva objetiva como autorregulación de relaciones jurídicas, patrimoniales." 
El elemento que prevalece en la definición de contrato es el de la consensualidad. Es decir, la noción de contrato gira alrededor del acuerdo de voluntades. Esto debido a que la autonomía de la voluntad es el fundamento sobre el cual se construye la definición de contrato en el derecho continental. De acuerdo a la definición de Fernando Hinestrosa la autonomía de la voluntad es entendida como: "El poder de darse así mismo normas, así, el o los sujetos negociales al disponer de sus intereses, estarían dictando normas de menor alcance, pero tan pertenecientes al derecho objetivo como las leyes" 32

Así las cosas, los límites que encuentra el sujeto al hacer uso su autonomía de la voluntad son dos: el primero de ellos es el orden público el cual hace referencia a los "Dictados políticos que señalan terminantemente la primacía del interés social sobre el individual y procuran enrumbar la actividad privada del modo que sea más conveniente para la comunidad entera, como se la considere ${ }^{33}$, en el momento y, según las circunstancias, más útil socialmente"; y el segundo hace referencia a las buenas costumbres que han sido definidas como "reglas morales, el sentido ético de la iniciativa particular" ${ }^{\prime \prime}$.

Además, el acuerdo de voluntades que da origen al contrato deberá cumplir con los requisitos de validez para que sea sujeto de protección jurídica. Para esto el contrato debe ser celebrado desprovisto de los vicios de la voluntad: error ${ }^{35}$, dolo $^{36} \mathrm{y}_{\text {fuerza }}{ }^{37}$ (o violencia). Lo anterior se debe a que el contrato debe nacer de un consentimiento libre, sano, ilustrado y genuino, como corresponde a una orientación de equilibrio y justicia contractual; de no tener estas características, el contrato será inválido.

\section{I+D como contrato en el common law}

A diferencia de lo que se entiende por contrato en el derecho continental, en el common law un contrato es una promesa o un conjunto de promesas cuyo rompimiento da un remedio. Es decir: A contract is a legally enforceable agreement. Dicha definición cuenta con dos elementos principales: el primero es el acuerdo de voluntades (agreement) y el segundo es la consideration ${ }^{38}$.

32 Hinestrosa, Fernando. Tratado de las Obligaciones ir. Negocio jurídico. Primera edición, Universidad Externado de Colombia, 2015, vol. I, p. 120. IsBn: 978-958-772-248-2.

33 Bianca, Massimo. Derecho Civil ini. El contrato. Op. cit., p. 46.

34 Ibíd., p. 24.

35 Hinestrosa, Fernando. Tratado de las Obligaciones it. Negocio jurídico. Op. cit., p. 943. "El error se define como discrepancia entre el concepto y realidad tener por cierto lo que no es, o por falso lo que es cierto, disconformidad entre el hecho y la idea que se tiene del él".

36 Ibíd., p. 1023. "El dolo consiste en cualquier clase de maniobras, maquinaciones, artificios, engaños, estratagemas, de que se vale alguien para obtener de otra persona la celebración de un negocio jurídico."

37 Ibíd., p. 1060. "Se entiende por fuerza la presión ejercida sobre una persona en razón de la cual esta celebra un negocio jurídico [...] dicha fuerza consiste en el temor que sobrecoge a la víctima y la lleva a optar por una determinada disposicion de intereses en razón del miedo que le infunde la amenaza de sufrir un daño."

38 Pérez García, Matías. Los elementos del contrato en la common law americana. En: 
El acuerdo o "agreement" hace referencia al convenio al que llegan las partes para obligarse mutuamente; dicho consenso no surge de un concurso de voluntades espontáneo, sino de una oferta y su aceptación. No hay contrato si no hay claridad y precisión, tanto en la oferta como en la aceptación. Es decir, el consentimiento debe expresarse de una manera muy precisa, a diferencia de lo que pasa en el derecho continental, en el cual cualquier declaración unilateral de la voluntad susceptible de ser coercible ${ }^{39}$.

En segundo lugar se encuentra el elemento de la consideration ${ }^{40}$, que surgió con el objetivo de explicar el carácter obligatorio del acuerdo y la reciprocidad de las prestaciones ${ }^{41}$ en el ordenamiento anglosajón ${ }^{42}$. La consideration establece que solo se puede hablar de contrato si existe un acuerdo entre individuos cuya contraprestación tenga valor económico ${ }^{43}$; de existir una convención que no cumpla con la anterior característica, corresponde a otra área del derecho ${ }^{44}$. Un ejemplo de ella sería: una promesa de $A$ a $B$ es contractualmente válida sólo si $B$ (el beneficiario ${ }^{45}$ de la promesa) ha hecho o promete hacer algo en beneficio de $A$ (el promitente) como contrapartida ${ }^{46}$.

Teniendo en cuenta lo expuesto, es posible afirmar que el acuerdo I+D pertenece a la categoría del contrato dado que este cumple con los requisitos de cada sistema legal para ser considerados como tal. Por un lado, en el sistema continental el I+D cumple con el requisito del consenso creador de obligaciones. Por otro lado, en el sistema del common law ocurre lo mismo, dado que el I+D contiene el elemento del agreement como con la consideration, toda vez que son acuerdos cuyas prestaciones tienen valores económicos.

Por último, es también necesario precisar que el I+D hace parte de la categoría del contrato de transferencia de tecnología. Esta categoría ${ }^{47}$ abarca todos aquellos acuerdos en los que una parte se obliga para con otra a realizar una prestación que recae sobre conocimientos científicos o tecnológicos, o de tecnología misma, concretándose con la transmisión del saber hacer o know-how, a cambio de una

Revista de derecho notarial mexicano Universidad Autónoma de México (UnAm), 2003, n. ${ }^{\circ}$ 118 , p. $127-158$.

39 Ibíd. "La oferta es una promesa obligatoria que debe ser apta para formar un contrato."

40 Ibíd. "También conocida como doctrina de la Consideration Se concibió en el common law como una herramienta para limitar la obligatoreidad de de una promesa. Dicha doctrina determina qué tipo de acuerdos se regulan bajo el estatuto jurídico de los contratos, otorgándoles a dichos acuerdos la protección que les corresponde como tales."

41 Sánchez, Lorenzo Sixto. El Derecho inglés y los contratos internacionales. En: Tirant lo Blanch, 2013, p. 49-55. Existe una tendencia a por ciertos autores de asimilar la noción de consideration a la de causa en el derecho continental.

42 Ibíd., p. 50.

43 Ibíd., p. 51. "No necesariamente la prestación debe ser dinero, debe ser avaluable en dinero."

44 Pino Alberto. Una aproximación continental al derecho inglés de los contratos. Una aproximación continental. En: Revista Chilena de Derecho Privado, julio 2014, n. ${ }^{\circ} 22$, p: $233-$ 253 "Los contratos a título gratuito se encuentran excluidos del ámbito contractual inglés."

45 Ibíd.

46 Ibíd.

47 Guerrero Gaitán, Manuel. Tipología de los contratos de transferencia de tecnología (en línea). En: Revista La Propiedad Inmaterial, 2009, n. ${ }^{\circ}$ 13, p. 204 (citado el 14 de junio del 2020). Disponible en: https://revistas.uexternado.edu.co/index.php/propin/article/view/461. 
prestación económica o regalía ${ }^{48}$, y el I+D es uno de ellos, debido a que el tipo de prestaciones de este acuerdo recae en su mayoría sobre la explotación de bienes inmateriales. Además de lo anterior, dicho acuerdo de voluntades también cuenta con las características propias de los contratos de transferencia de tecnología, siendo un contrato a típico, consensual, sinalagmático y oneroso ${ }^{49}$.

Ya establecido que el I+D es un contrato, y que dicha definición se aplica tanto para el derecho continental como para el common law, se expone a continuación el contenido del contrato objeto de este trabajo.

\section{CONTENIDO ${ }^{50}$}

Uno de los primeros esbozos que se pueden dar del contenido del contrato I+D se corresponde con la definición de este: “R\&D alliances are innovations based relationships formed by two or more partners who pool their resources and coordinate their activities to reach a common goal" 51 . Sin embargo, este acercamiento no es suficiente para entender en su totalidad de qué se trata el contrato, cuál es su funcionalidad. Para lograr esto, se acude a la noción de contenido, la cual para efectos del presente escrito comprende las características del acuerdo, el objeto, el contenido prestacional y la tipología de este.

\section{A. CARACTERÍSTICAS}

El contrato $i+d$ es una figura flexible que se configura de múltiples maneras; debido a esto existen diferentes tipos de $\mathrm{i}+\mathrm{d}$. A pesar de lo anterior, es posible señalar las características generales de las cuales goza este tipo de contrato. Estas son:

- Acuerdo de cooperación: El contrato I+D es un acuerdo de cooperación debido a que es un contrato que se realiza entre dos o más partes independientes que, uniendo o compartiendo parte de sus capacidades o recursos sin llegar a fusionarse, establecen un cierto grado de interrelación para realizar una o varias actividades que contribuyan a incrementar sus ventajas competitivas. Dichos acuerdos están encaminados, bajo ciertas condiciones, a reducir los costes de transacción en los que se habría incurrido si la operación económica hubiese tenido lugar a través del mercado y al mismo tiempo para evitar ciertos costes de organización que hubieran surgido

48 Martínez-Pacheco, Belkys, Vargas-Chaves, Iván, Eduardo Salgado-Figueroa. El contrato de transferencia de tecnología: caracterización e importancia estratégica (en línea). En: Revista brasilera de direito capes qualis, 2018, vol. 14, n.o 2, p. 26 (consultado el 15 de junio del 2020). Disponible en: https://seer.imed.edu.br/index.php/revistadedireito/article/view/2942/.

49 Guerrero, Gaitán Manuel. Tipología de los contratos de transferencia de tecnología. Op. cit., p. 204-206.

50 Bianca, Massimo. Derecho Civil in. El contrato. Op. cit., p. 340. "El contenido del contrato comprende lo que las partes establecen con miras, bien a los resultados materiales bien a los efectos jurídicos. [...] el contenido del contrato expresa la decisión de las partes".

51 Martínez Noya, Andrea, y Narula, Rajneesh. What more can we learn from R\&D alliances? A review and research agenda. Op. cit., p. 196. 
si los servicios que se pretendían contratar hubiesen sido totalmente internalizados por el seno de una compañía.

- Atípico ${ }^{52}$ : El I+D es un contrato atípico debido a que los elementos sustanciales o esenciales que individualizan o diferencian a esta clase de acuerdo no se encuentran recogidos y menos regulados de manera suficiente y completa en el ordenamiento positivo $^{53}$. En esta materia el mayor problema es la dificultad para resolver las controversias que surgen con ocasión de estos acuerdos, ya que, los elementos esenciales de este tipo de contratos no se encuentran consagrados en ninguna disposición. Sin embargo, la doctrina está de acuerdo en que los particulares no pueden obrar con plena libertad en este escenario, por lo cual basta con recordar que los contratos atípicos, en primer lugar están sometidos a los principios generales y, en segundo lugar, los acuerdos de este tipo tienen que cumplir con una función relevante a los ojos del derecho y de ordinario deben estar singularmente dirigidos a la satisfacción de intereses dignos de tutela por parte del ordenamiento jurídico ${ }^{54}$. Por último, la jurisprudencia ha desarrollado criterios, tales como la analogía para resolver los conflictos que surjan en este tipo de contratos ${ }^{55}$.

- Bilateral: Un contrato bilateral es aquel celebrado por dos o más individuos en el cual cada parte está obligada a una prestación. Sin embargo, lo anterior no basta para caracterizar un contrato bilateral, sino que es necesario que las prestaciones estén en relación de interdependencia o reciprocidad entre sí, de modo que cada prestación es presupuesto necesario de la prestación de la otra parte. Es decir, cada parte es deudora y acreedora en él ${ }^{56}$. Dicha reciprocidad también implica que desde el nacimiento mismo del contrato surjan simultáneamente obligaciones para ambos extremos de la relación contractual ${ }^{57}$.

52 Camacho lópez, María Elisa. Régimen jurídico aplicable a los contratos atípicos en la jurisprudencia colombiana (en línea). En: Revista Mercatoria, 2005, vol. 4, n. ${ }^{\circ} 1$, p. 2 (consultado el 15 de junio del 2020). Disponible en: https://revistas.uexternado.edu.co/index. php/emerca/article/view/2106 "al hablar de tipicidad nos estamos refiriendo a la regulación que hace el ordenamiento jurídico, sin especificar la fuente que cumple dicha función, por lo que debemos entender que esa tipificación se puede presentar por medio de la ley, pero también por otras fuentes del derecho. De ahí que la doctrina clasifique la tipicidad en social y legal, comprendiendo por la primera aquella que se hace a través de la ley, y por la segunda, aquella que proviene de fuentes diferentes a la legal, comúnmente, por medio de la costumbre y la jurisprudencia”.

53 Ibíd., p. 11.

54 Sconamilio, Renato. Teoría General del Contrato. Primera edición, Milán: Casa Editorial Dr. Francesco vallard. 1961, p. 183.

55 Camacho López, María Elisa. Régimen jurídico aplicable a los contratos atípicos en la jurisprudencia colombiana. Op. cit., p. 24. "La mayoría de los autores explican la teoría de la absorción como aquella en la cual se debe aplicar al contrato las normas correspondientes al contrato típico del cual provenga el elemento o prestación prevalente en ese contrato atípico, en otras palabras, conforme a esta teoría el juzgador deberá establecer cuál es el elemento que en ese contrato prevalece sobre los demás y de acuerdo con esa información, aplicar las normas del contrato al cual pertenece aquel."

56 Melich Orsini, José. Doctrina general del contrato. Tercera edición, Caracas, Venezuela: Editorial jurídico-venezolana Marcial Pons, 1997, p. 50-51. ISBN: 9789800741375.

57 Neme Villarreal, Martha Lucía. Carácter sinalagmático perfecto de los contratos unilaterales: una lectura a partir de la función de los contratos. En: Obligaciones, contratos, responsabilidad. Grupo para la armonización del derecho privado latinoamericano. Bogotá: 
- Oneroso: Se dice que un contrato es oneroso cuando ambas partes incurren en un "sacrificio" económico para conseguir como contrapartida una utilidad de la relación contractual ${ }^{58}$. Una parte de la doctrina sostiene que la característica de onerosidad no se agota en lo anteriormente dicho, sino que se debe también tener en cuenta la equivalencia de los sacrificios y la utilidad que las partes reciben ${ }^{59}$.

- Tracto sucesivo: Son aquellos contratos cuyo cumplimiento supone la ejecución de prestaciones sucesivas durante un periodo de tiempo prolongado ${ }^{60}$.

- Intuito personae: La medida en que se llevan a cabo atendiendo a las especiales cualificaciones tanto del productor como del receptor de la tecnología objeto del acuerdo $^{61}$.

Por último, tal y como se puede apreciar en la imagen, el acuerdo I+D es apenas uno de los contratos utilizados en el proceso de creación e innovación tecnológica. Lo anterior quiere decir, por un lado, que varios contratos le pueden preceder y anteceder, y, por otro lado, que la función del contrato se circunscribe únicamente a regular la etapa de investigación y creación de tecnología. Debido a lo anterior se deduce que si las partes quieren, por ejemplo, comercializar dicha tecnología, deben acudir a otras figuras contractuales.

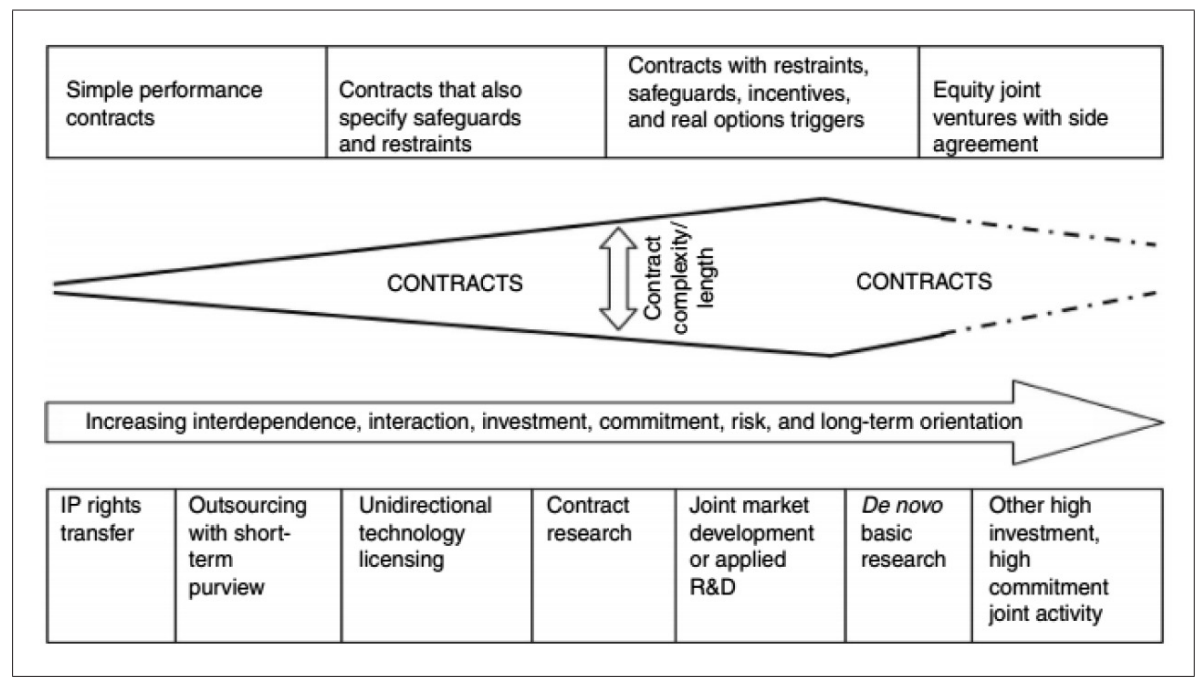

Fuente: Martínez-Noya, A., \& Narula, R. (2018). What more can we learn from R\&D alliances? A review and research agenda. BRQ Business Research Quarterly.

Universidad Externado de Colombia, 2011. Memorias del encuentro del mismo nombre realizado en Bogotá en 2009, p. 424

58 Ospina Fernández, Guillermo, Ospina Acosta, Eduardo. Teoría general de los actos o negocios jurídicos. Bogotá: Editorial Temis, 1980, p. 5.

59 Melich Orsini, José. Doctrina general del contrato. Op. cit., p. 55.

60 Ospina Fernández, Guillermo, Ospina Acosta, Eduardo. Op. cit., p. 75.

61 Guerrero, Manuel. 2009. Op. cit., p. 204. 


\section{B. ОВJЕTO ${ }^{62}$}

La noción de objeto del contrato en el derecho continental es ampliamente discutida. La razón de esto reside en la ambigüedad del término, toda vez que en materia contractual la expresión objeto es utilizada para significar ya sea la prestación ${ }^{63}$, el bien económico de una transacción u otras situaciones ${ }^{64}$. Para efectos del presente escrito se define al objeto del contrato como el contenido sustancial de este, es decir, aquello que las partes establecieron o a lo que se obligaron en el contrato ${ }^{65}$. Así las cosas, en el caso del $\mathrm{I}+\mathrm{D}$ el objeto del contrato es invertir o aportar recursos ya sea en dinero o en especie, con el fin de realizar un proyecto conjunto de investigación científica o de desarrollo de una tecnología ${ }^{66}$. Dicho contrato se diferencia de otras figuras a fines como el joint venture por ser un non equity alliance $^{67}$, lo cual quiere decir que en este tipo de contratos la responsabilidad de las partes no se ve limitada por los aportes hechos, y de igual manera la distribución del riesgo ${ }^{68}$ entre las partes es asumida individualmente ${ }^{69}$.

62 Fiori, Roberto. El problema del objeto del contrato en la tradición civil (en línea). En: Revista de Derecho Privado Universidad Externado de Colombia, 2007, n. ${ }^{\circ}$ 12, p. 253 (consultado el 15 de junio del 2020). Disponible en: https://revistas.uexternado.edu.co/index. $\mathrm{php/derpri/article/view/565.} \mathrm{"La} \mathrm{categoría} \mathrm{objeto} \mathrm{del} \mathrm{contrato} \mathrm{es} \mathrm{un} \mathrm{producto} \mathrm{histórico} \mathrm{que} \mathrm{se}$ formó a merced de la confluencia de factores con naturaleza y proveniencia diversas. El uso práctico de los modelos del derecho romano fuera de su contexto, la interpretación secular de estos modelos con lentes simpre distintos. [...] Un uso de la categoría que prescinda de su historia impensable."

63 Ibíd. "Otros prefirieron pensar en la prestacion. Sin embargo, esta perspectiva se opone al hecho de que en nuestro ordenamiento existen contratos con efectos reales en los cuales se puede hablar de prestación solo ampliando la última noción al punto de hacer entrar en ella también la transferencia de derechos."

64 Ibíd. "En la interpretación de estos datos, algunos estudiosos se han dirigido, sin más hacia la noción de bien. No obstante, a la teoría se han opuesto diversas objeciones: ante todo que en tales casos no se reconoce en el contrato bien alguno, sino derechos y obligaciones, de modo en que estas hipótesis el contrato sería nulo dada la ausencia de uno de sus elementos esenciales."

65 Bianca, Massimo. Derecho Civil ini. El contrato. Op. cit., p. 343.

66 Buss, Philip, Peukert, Christian. R\&D outsourcing and intellectual property infringement. En: Research Policy, 2015, vol. 4, n. ${ }^{\circ}$ 4, p. 3. "We can think of R\&D as a process starting with basic research, then combining technical inventions and designs to develop the final product. In early stages, technical inventions and perhaps to a lesser degree also designs constitute generic knowledge that potentially has more than one application. In later stages however, it takes a specific combination of inventions, designs, and perhaps marketing to define a differentiated product."

67 T. K. DAs. A Resource-Based Theory of Strategic Alliances. En: Journal of Management 2000, vol. 25, n. ${ }^{\circ}$ 4, p. 43. "Strategic alliances can take a variety of forms, including, but not limited to, joint ventures, minority equity alliances, R\&D contracts, joint R\&D, joint production, joint marketing and promotion, enhanced supplier partnership, distribution agreements, and licensing agreements. In an effort to better organize such a large collection of alliance forms, theorists have proposed several typologies of strategic alliances [...] Most studies on alliance structural choice have been based on the dichotomy of equity alliance vs nonequity alliances [...] Non equity alliances refer to all other cooperative arrangements that do not involve equity exchange."

68 Alcácer, Juan, Chung, Wilbur. Location strategies and knowledge spillovers. En: Management Science 2007, vol. 53, p. 761-762. "For example one of the most common risks in this type of contract is the risk of inadequate uses or modifications of the knowledge transferred that may leave the transferor worse off. Such a risk occurs either when the recipient partner takes advantage of that acquired knowledge to become a future competitor or (2) the knowledge gained by the recipient partner may benefit competitors with whom they may also be engaged with." 


\section{PARTES}

Generalmente, son dos las clases de individuos que suscriben contratos I+D: Las compañías grandes o pequeñas y las universidades ${ }^{70}$. Esto, se debe al modelo sistémico de transferencia de tecnología que ha ganado acogida en los últimos años, el cual propende a que los principales productores de conocimiento, entiéndase las compañías y las universidades, realicen estrategias de cooperación entre ellas y con el Estado, manteniendo su autonomía ${ }^{71}$.

De acuerdo con lo anterior, la primera clase de individuos que hacen uso de los acuerdos I+D son personas jurídicas de mediana o larga escala, las cuales pertenecen usualmente al sector tecnológico, y buscan obtener resultados elevados en eficiencia de manera rápida, destinando una parte de sus ganancias a financiar investigaciones conjuntas con otras compañías, dinero que antes destinaban únicamente a la investigación in-house ${ }^{72}$.

Los acuerdos de I+D celebrados entre las compañías están sujetos exclusivamente a las normas de derecho comercial y derecho privado. No obstante, también es posible que personas naturales suscriban contratos $\mathrm{I}+\mathrm{D}$ entre ellas o entre ellas y compañías, acuerdos que también se regularán exclusivamente por las disciplinas del derecho comercial y civil $^{73}$.

La segunda clase de individuos que hacen uso de los contratos I+D son las universidades, ya sean públicas o privadas, entidades que al tener un importante papel en la sociedad, como lo es la formación académica de los individuos y la investigación científica, se ven en la obligación de mantenerse a la vanguardia de los desarrollos tecnológicos y de la innovación. Lo anterior comporta un alto grado de dificultad sobre todo debido a los altos costos de la innovación, por lo cual las universidades acuden a la figura del I+D. Estas instituciones no están sometidas únicamente a las normas del derecho privado a la hora de suscribir un acuerdo de $\mathrm{I}+\mathrm{D}$, sino que

69 Hagedoorn, J. Organisational modes of inter-firm cooperation and technology transfer'. En: Technovation 1990, vol. 10, n. ${ }^{\circ}$ 1, p. 17-31. "Non-equity partnerships are 'pure hybrid forms' which do not include the creation of a new venture. Property rights and profit allocation schemes do not ensue from shareholdings and residual rights of control are thus not automatically accounted for."

70 So, Soнn y Mоочеов, Lee. Conjoint analysis of R\&D contract agreements for industryfunded university research. En: The Journal of Technology Transfer, Springer, 2012, vol. 37, n. ${ }^{\circ}$ 4, p. 532. "[...] Since the late nineteenth century, universities have been regarded as useful sources of technological development to stimulate economic activity. [...].”

71 Aceytuno, María-Teresa, Cáceres, F. Rafael, Los modelos europeos de transferencia de tecnología universidad-empresa (en línea). En: Revista de Economía Mundial 2012 (consultado el: 17 de mayo de 2019). Disponible en: http://www.redalyc.org/articulo.oa?id=86625395009 . "El enfoque sistémico trata de incorporar al análisis todos los determinantes de la innovación que tienen una cierta relevancia -económicos, sociales, institucionales, etc.- enfatizando la idea de interdependencia entre los mismos frente a una visión lineal de proceso innovador."

72 Ibíd. Un ejemplo de esto se da en el sector farmacéutico, debido a la constante presión de encontrar nuevos medicamentos a la que se ven sometidas las compañías.

73 Anderson, Mark. Technology transfer law practice and precedents. United Kingdom: Tottel publishing, 2010, segunda edición, p. 4. 
también se acogen a las disposiciones de derecho público que limitan el alcance de esta clase de acuerdos ${ }^{74}$.

\section{Obligaciones de las partes}

Los contratos de I+D están conformados por dos o más individuos. En principio todas las partes que componen el acuerdo se ven obligadas a:

\section{a. Realizar un aporte ya sea en especie o en dinero}

Esta obligación hace referencia al deber que adquieren las partes de contribuir a la sostenibilidad económica de la investigación. Dicha contribución pude ser en especie, es decir todos aquellos recursos que no sean dinero, pero sean susceptibles de ser avaluados económicamente, en este caso suele ser mano de obra calificada e instalaciones adecuadas para realizar la investigación, el licenciamiento de conocimientos o dinero. Así las cosas, esta obligación se entiende cumplida únicamente si los recursos que aportan las partes se utilizan exclusivamente para sufragar los gatos de la investigación Una forma en que se concreta esta obligación durante la ejecución del contrato es, por ejemplo, con la creación de comités integrados por representantes de cada parte, quienes se encargan de distribuir los gastos y de realizar aportes periódicos sobre el avance de la investigación ${ }^{75}$.

\section{b. Realizar una investigación conjunta}

Esta es una obligación de hacer, lo cual implica que las partes deben desplegar un comportamiento encaminado al desarrollo y la ejecución de la investigación. De igual forma, la obligación debe ser ejecutada de acuerdo con el principio de la buena fe, lo cual tiene como consecuencia que todas las conductas desplegadas por las partes con el fin de realizar la investigación deben realizarse de forma diligente, y deben estar encaminadas al exitoso desarrollo de la investigación. Lo anterior se ve, por ejemplo, en la elaboración de cronogramas y el diseño de planes de investigación y metodología para lograr desarrollar el proyecto o en mantener informadas a todas las partes sobre el desarrollo y la ejecución de la investigación ${ }^{76}$. Esta clase de obligación se concreta en el siguiente tipo de cláusula:

[T] he clauses that define how the relationship is to be managed (e.g., stipulating the existence of committees, the number of meetings, the number of work hours to be performed, or the names of scientists assigned to the project) are called coordination

74 Ibíd.

75 Ibíd., p. 69.

76 Francia. Ministère de l'Éducation nationale. Ministere de l'ensseignement supérieur de la recherche. Guide pratique sur la gestión des contrats relarifs aux activités de recherche. Groupe de travail.- Daf 2017, p. 11. 
clauses (Lumineau \& Malhotra, 2011), and are unenforceable (Tirole, 1999). In other words, there are no explicit mechanisms to monitor these stipulations ${ }^{77}$.

\section{c. Suministrar la información que sea necesaria para desarrollar la investigación}

La presente es una obligación de hacer, lo cual implica que las partes desplieguen un comportamiento encaminado a brindar y colaborar con la información necesaria para que se realice la investigación o el proyecto de $\mathrm{I}+\mathrm{D}$ de acuerdo con los lineamientos pactados por las partes. Dicha información comprende no solo datos científicos sino también en el caso de las empresas, información sobre procesos de distribución y funcionamiento de las compañías ${ }^{78}$.

\section{d. Ser diligente con el manejo de la información aportada por las partes que conforman el contrato}

Así como las partes están en la obligación de brindar información, también están en la obligación de salvaguardar la información proporcionada por las demás partes en el marco del contrato. La información que las partes aportan en el marco de los acuerdos de $\mathrm{I}+\mathrm{D}$ es protegida dependiendo de su naturaleza, que puede ser información técnica relacionada con datos científicos necesarios para el desarrollo de la investigación conjunta o información referida a la naturaleza, características o finalidades de los productos; o los métodos o procesos de producción; o esquemas de administración y prestación de servicios de una de las partes.

La forma más apropiada de permitir el uso de la información técnica que aportan las partes es a través de un contrato de licencia ${ }^{79}$ o de las disposiciones consagradas en el mismo contrato I+D. Por medio de estas figuras contractuales el individuo puede autorizar y limitar el uso que se le dé a la tecnología en el marco de la investigación conjunta.

77 Delerue, Hélène. Shadow of joint patents: Intellectual property rights sharing by SMEs in contractual R\&D alliances. En: Journal of Business Research 2018, vol. 87, p. 13.

78 Cantwell, John, D. Santangelo, Grazia. The frontier of international technology networks: sourcing abroad the most highly tacit capabilities. En: Information Economics and Policy 1999, vol. 11, p. 101-123. “R\&D alliances present many managerial challenges in their effective design and management. This is so because R\&D alliances tend to require the exchange of tacit and firm-specific knowledge that includes hard-to communicate skills or know-how that is difficult to codify and is better transferred through close interaction When partners cannot clearly define property rights over knowledge, it becomes difficult for them to establish knowledge transfer barriers."

79 Guerrero Gaitán, Manuel. Los contratos de transferencia internacional de tecnología América Latina, Estados Unidos y la Unión Europea. cit., p. 57. "La licencia es una de las figuras contractuales más utilizadas en la contratación internacional de transferencia de tecnología, puesto que puede ser utilizada como una herramienta para autorizar el uso de diferentes bienes inmateriales tales como invenciones no patentadas, solicitudes de patente, secretos empresariales, trazados topográficos de circuitos integrados, derechos de obtentor de variedades vegetales, derechos de autor [...]." 
Por otro lado, la información que proporcionan las partes relacionadas con su funcionamiento y sus procesos de producción se protege a través de cláusulas o acuerdos de confidencialidad, en los cuales se estipula el manejo que se le debe dar a la información y las consecuencias que conlleva el mal manejo de esta. De incumplirse estas disposiciones, la parte afectada puede acudir a la figura de secreto empresarial ${ }^{80}$, categoría que busca proteger el conjunto de datos de carácter comercial $^{81}$ o productivo sobre el que pesa una reserva en su divulgación dada su importancia económica para la empresa, y permite que quien divulgue este tipo de información sea sancionado judicial y administrativamente ${ }^{82}$.

\section{e. Establecer con claridad la distribución y el manejo que se les darán a los derechos de propiedad intelectual utilizados para y derivados de la investigación}

En una alianza establecida mediante un acuerdo I+D, las partes tienen como objetivo desarrollar conjuntamente una tecnología o una investigación con el fin de producir un nuevo conocimiento. Sin embargo, es común que conforme avanza la investigación sea cada vez más difícil diferenciar aquellos conocimientos que fueron aportados por las partes de aquellos nuevos que se generan como producto de la investigación debido a la multiplicidad de derechos de propiedad intelectual que se generan en este tipo de relaciones. Esto tiene como consecuencia que sea muy difícil establecer la titularidad de los derechos de propiedad intelectual de las partes que intervienen.

80 Decisión 486 de 2000 de la Comunidad Andina de Naciones, artículo 260: "Se considerará secreto empresarial cualquier información no divulgada que una persona natural o jurídica legítimamente posea, que pueda usarse en alguna actividad productiva, industrial o comercial, y que sea susceptible de transmitirse a un tercero, en la medida que dicha información sea: a) secreta, en el sentido que como conjunto o en la configuración y reunión precisa de sus componentes, no sea generalmente conocida ni fácilmente accesible por quienes se encuentran en los círculos que normalmente manejan la información respectiva; b) tenga un valor comercial por ser secreta; y c) haya sido objeto de medidas razonables tomadas por su legítimo poseedor para mantenerla secreta. La información de un secreto empresarial podrá estar referida a la naturaleza, características o finalidades de los productos; a los métodos o procesos de producción; o, a los medios o formas de distribución o comercialización de productos o prestación de servicios”.

81 Payán Rodríguez. Secreto empresarial, vigencia como mecanismo de protección en la propiedad intelectual (en línea). En: Revista La Propiedad Inmaterial, n. ${ }^{\circ} 15$ (consultado el 15 de junio del 2020), p. 207-24. Disponible en https://revistas.uexternado.edu.co/index.php/ propin/article/view/3006. "La esfera jurídica, el secreto desempeña un importante y complejo papel; por eso las normas jurídicas establecen diferentes modos de protección."

82 Pooley, James. El secreto comercial el otro derecho de P. I. ompi (en línea). Junio 2013 (consultado el 15 de junio del 2020). Disponible en: https://www.wipo.int/wipo_magazine/ es/2013/03/article_0001.html. "En 1995 se crearon normas internacionales para la protección de secretos («información no divulgada») en el marco del Acuerdo sobre los ADPIC. El artículo 39 del acuerdo establece que los Estados miembros protegerán la «información no divulgada" contra el uso no autorizado "de manera contraria a los usos comerciales honestos» (esto incluye el incumplimiento de contratos, el abuso de confianza y la competencia desleal). La información no debe ser generalmente conocida ni fácilmente accesible, debe tener un valor por ser secreta, y debe ser objeto de «medidas razonables» para mantenerla en secreto. Esta fórmula general de las leyes sobre secretos comerciales ha sido adoptada por más de 100 de los 159 miembros de la Organización Mundial del Comercio." 
Con el fin de evitar la situación anteriormente descrita, las partes se ven en la obligación de establecer con claridad la distribución y manejo que se le darán a los derechos de propiedad intelectual utilizados para y derivados de la investigación. Para lo cual es menester diferenciar entre los derechos de propiedad intelectual ex ante y ex post ${ }^{83}$. Los derechos de propiedad ex ante son aquellos derechos de propiedad intelectual que están en cabeza de las partes al iniciar la investigación, es decir, son los conocimientos y los avances tecnológicos que cada parte del contractual aporta con el propósito de iniciar la investigación ${ }^{84}$. Los derechos ex post son aquellos activos de propiedad intelectual que se generan en el curso o como resultado de las investigaciones.

Una vez diferenciados los derechos de propiedad intelectual ex ante y expost, se debe aclarar quién es el titular de cada uno y el uso y tratamiento que se le dará a cada uno. En el caso de los derechos ex ante no existe discusión frente a su titularidad, siempre y cuando la parte propietaria de la tecnología acredite serlo (ya sea por medio de una patente, un modelo de utilidad, etc.) y especifique el uso que se le puede dar al conocimiento que se aporta a la investigación conjunta, lo cual generalmente se logra licenciando la tecnología.

Por otro lado, el manejo que se les da a los derechos de propiedad intelectual ex post es más complejo, toda vez que, en primer lugar, no se tiene certeza de cuáles serán, cuándo se producen o de su naturaleza; $y$, en segundo lugar, su naturaleza es variada, debido a que los derechos que se desprenden de las investigaciones pueden ser desde el derecho del investigador a publicar hasta patentar una invención ${ }^{85}$. A pesar de lo difícil que resulta regular este tipo de derechos, es necesario hacerlo con el fin de evitar situaciones de abuso o desequilibrio contractual, pues de guardar silencio frente a la distribución de esta clase de derechos, las partes no tienen un marco de protección que resulte justo para quienes participan en estas alianzas. Dicha asignación de recursos se realiza a través de cláusulas de control de derechos o "control clauses".

Por último, cabe resaltar que las obligaciones derivadas del contrato de $\mathrm{I}+\mathrm{D}$ deben ejecutarse e interpretarse a la luz del principio de buena fe, el cual integra el contenido del contrato mediante la adición del contenido contractual, y también lo hace mediante la exclusión o modificación de las cláusulas contenidas en el acuerdo, como en el caso de la aplicación de la cláusula rebus sic stantibus o teoría de la imprevisión y la anulación de cláusulas abusivas ${ }^{86}$.

83 Delerue, Hélène et Lejeune, Albert. Joint Patenting in R\&D Alliances: Control Rights and Resource Attributes. En: Management 2013, vol. 16, p. 116.

84 Ibíd.

85 Martínez Noya, Andrea, y Narula, Rajneesh. What more can we learn from R\&D alliances? A review and research agenda. En: Business Research Quarterly. Op. cit., p. 200. 86 Neme Villarreal, Martha Lucía. El principio de buena fe en materia contractual en el sistema jurídico colombiano. En: Revista de Derecho Privado, 2006, n. ${ }^{\circ} 11$, p. 90 (consultado el: 15 de junio del 2020). Disponible en: https://revistas.uexternado.edu.co/index. $\mathrm{php/derpri/article/view/575.}$ 
En este sentido se ha pronunciado la jurisprudencia colombiana, para la cual la buena fe comporta la obligación de cumplir las prestaciones con lealtad, honestidad y moralidad, además de señalar que la fuerza obligatoria de los contratos consagrada en el artículo 1602 C. C. colombiano comporta que ${ }^{87}$

se deriva la necesidad, para cada uno de los contratantes, de ejecutar su prestación de conformidad con una serie de reglas jurídicas que son aplicables, unas, a todos los contratos, y otras, a los contratos sinalagmáticos únicamente. Las reglas aplicables a todos los contratos son estas: a) Las convenciones deben ser ejecutadas de buena fe, lo que vale decir que los contratantes deben proceder honesta y lealmente y ajustándose en un todo a los dictados de la equidad, y que deben cumplir sus obligaciones y ejercitar sus derechos sobre la base de que, habiendo sido como fue consagrada por la ley la obligación en razón de su utilidad social, no se puede abusar del derecho ni perder de vista la finalidad de la convención. b) El deudor de la obligación debe poner, en el cumplimiento de ésta, la diligencia y el cuidado de un buen padre de familia, cuando se trata de convenciones como la que se estudia, hechas en beneficio recíproco de las partes ${ }^{88}$.

\section{TIPOLOGÍA}

A pesar del amplio uso que tienen los acuerdos de $\mathrm{I}+\mathrm{D}$, actualmente no existe una clasificación universal de este tipo de contratos ${ }^{89}$, lo cual ha generado que existan múltiples clasificaciones (a veces disimiles) de este tipo de acuerdos. Así las cosas, se propondrá una clasificación en función de la extensión y el alcance de la colaboración en este tipo de contratos.

Los acuerdos de I+D pueden ser de dos tipos ${ }^{90}$ :

\section{A. I+D DE FINANCIACIÓN ${ }^{91}$}

Son acuerdos en los que existen dos partes. Una parte denominada "researching party" (o en español, parte investigadora), que se obliga a realizar un proyecto de investigación y desarrollo y otra parte denominada "funding party" (o en español, financiador), que se obliga a suministrar una parte del capital necesario para costear los gastos del I+D y a apoyar de forma subsidiaria con información tecnología a la investigación. Lo que distingue a este $\mathrm{I}+\mathrm{D}$ de otros es el contenido y la extensión

87 Ibíd.

88 Corte Suprema de Justicia, Sala de Casación Civil. Sentencia del 29 de febrero de 1936, M. P.: Eduardo Zuleta Ángel.

89 Martínez Noya, Andrea, y Narula, Rajneesh. What more can we learn from R\&D alliances? A review and research agenda. En: Business Research Quarterly. Op. cit., p. 204. 90 Anderson, Mark. Technology transfer law practice and precedents. Op. cit., p. 69.

91 Francia. Ministère de l'Éducation nationale. Op. cit., p. 9. "[...] il s'agit d' une aide financiére allouée par un bailleur en vue de financer un projet de recherche, donc conditioneé par une obligation de moyens [...]." 
de la cooperación, toda vez que en este tipo de contratos la cooperación se enfoca principalmente en la financiación que una de las partes hace al I+D de la otra ${ }^{92}$.

Sin embargo, frente a la extensión de la obligación de financiar en este tipo de acuerdos, existen dos posturas. Por un lado, se encuentran aquellos que sostienen que la extensión de la obligación de financiar se agota al momento en que la parte da el dinero para realizar el $\mathrm{I}+\mathrm{D}$, pudiendo esta solamente solicitar información de los avances del I+D y de la destinación de los recursos económicos al I+D. Sin embargo, en ninguna circunstancia el financiador puede hacerse propietario de la propiedad intelectual que genere a partir del $\mathrm{I}+\mathrm{D}^{93}$., Por otro lado, están aquellos que sostienen que el alcance de la obligación de financiar no se agota en solo dar un aporte en dinero, sino que de ella se desprenden otras obligaciones y facultades; por ejemplo, la parte que financia tiene injerencia directa en el contenido y dirección de la investigación del I+D, y tiene la posibilidad de negociar derechos de propiedad intelectual con la parte investigadora ${ }^{94}$.

\section{B. I+D DE COLABORACIÓN}

A diferencia de los acuerdos de financiamiento, los I+D de colaboración están conformados por dos o más partes, que se obligan a cooperar con el fin de realizar un I+D. Dicha cooperación se entiende en un sentido amplio ${ }^{95}$ toda vez que son todas las partes quienes se encargan de la financiación del proyecto, de la dirección del I+D y de la distribución de derechos de propiedad intelectual ${ }^{96}$. Esta categoría a la vez se clasifica en función de los sujetos, de la siguiente manera ${ }^{97}$ :

\section{1. $I+D$ verticales $^{98}$}

Es un contrato de I+D colaborativo que se da entre una compañía y aquellos sujetos que intervienen a lo largo del desarrollo de la cadena de valor de un producto, tales como proveedores (competidores indirectos). Ambas partes cooperan la una

92 Esta modalidad es utilizada sobre todo en las investigaciones conjuntas en las que una parte es una entidad estatal. Por ejemplo, en Colombia el Ejército suele desarrollar tecnología de manera conjunta con universidades, mediante acuerdos R\&D, en donde el Ejército aporta la mayoría del capital para la investigación y de igual forma apoya en menor mediada al proceso de la investigación.

93 Ministère de l’Éducation nationale. Op. cit., p. 9. "Por ejemplo en Francia, cuando es un privado quien hace las veces de financiador, un proyecto de investigación de una universidad pública no se le permite hacerse propietario de la propiedad intelectual, que eventualmente pueda desarrollarse.”

94 Anderson, Mark. Technology transfer law practice and precedents. Op. cit., p. 69.

95 Ministère de l'Éducation nationale. Op. cit., p. 9.

96 Anderson, Mark. Technology transfer law practice and precedents. Op. cit., p. 69.

97 Belderbos, Rene et al. Cooperative R\&D and firm performance. En: Elsevier Katholieke Universiteit Leuven, Faculty of Economics 2004, vol. 22, p. 478.

98 Tether Bruce. Who co-operates for innovation, and why an empirical analysis. En: Research Policy, 2002, vol. 31, n. ${ }^{\circ}$ 6, p. 947-967. 
con la otra para participar en el desarrollo de investigaciones o tecnología con los objetivos de reducir costos de producción y expandir el mercado de un producto ${ }^{99}$.

\section{2. $I+D$ horizontales}

Son contratos de $\mathrm{I}+\mathrm{D}$ en los cuales dos partes que podrían ser competidores directos se colaboran mutuamente con el fin de desarrollar una investigación o una tecnología conjunta ${ }^{100}$. Estos acuerdos tienen dos objetivos. En primer lugar, enfrentar los desafíos o problemas que afectan a todos los competidores directos de un determinado sector del mercado. Esta situación se da cuando un sector del mercado debe realizar configuraciones a los bienes o servicios que produce, con el fin de que estos se adapten al estándar establecido por las entidades estatales ${ }^{101}$. Generalmente, el costo de las adaptaciones o exigencias es muy elevado o complejo de desarrollar, y ante estos obstáculos una de las mejores posibilidades es establecer alianzas con individuos que se enfrentan al mismo problema. Un ejemplo de esto se da en el sector del automóvil, en donde los estándares de control de polución son cada vez más estrictos para los vehículos. Y las empresas de esta industria se ven en la necesidad de colaborarse en la producción de productos que cumplan con las exigencias de la normativa medioambiental.

En segundo lugar, los acuerdos de I+D horizontales tienen como objetivo ampliar la base de mercado de las compañías. Esto se logra a través de las investigaciones conjuntas entre empresas que si bien pertenecen al mismo sector no desarrollan las mismas actividades y buscan con esta unión crear un nuevo producto que combine los servicios y productos que estas ofrecen ${ }^{102}$.

Un ejemplo de lo anterior es el caso de Sony, una de las principales compañías productoras de artefactos tecnológicos tales como chips, computadores, televisores, etc., $\mathrm{y}$ Microsof ${ }^{103}$, uno de los principales desarrolladores de software. A comienzos del año 2019 ambas empresas firmaron un acuerdo I+D que tiene como objetivo crear y ofrecer contenidos de ocio digital, lo cual es posible debido a que Sony es el principal productor de chips semiconductores y de sensores inteligentes de

99 Buss, Philip, Peukert, Christian. R\&D outsourcing and intellectual property infringement. En: Research Policy. Op. cit., p. 2. "The classical argument in favor of outsourcing is that specialized suppliers can realize economies of scale and hence produce at lower cost. In turn, firms that outsource operate more efficiently. A growing empirical literature highlights that this mechanism also works concerning the production of knowledge by showing a positive link between knowledge-intensive outsourcing and innovation performance."

100 Tether, Bruce. Who co-operates for innovation, and why an empirical analysis. Op. cit., p. 947-967.

101 Ibíd.

102 Ibíd.

103 Microsoft News Center. Sony and Microsoft to explore strategic partnership (en línea) (consultado el 16 de mayo de 2019). Disponible en: https://news.microsoft.com/2019/05/16/sonyand-microsoft-to-explore-strategic-partnership/. 
imagen, y Microsoft es el creador del sistema de inteligencia artificial de plataformas digitales, elementos que se combinaran para cumplir con el objetivo ${ }^{104}$.

Sin embargo, los contratos de $\mathrm{I}+\mathrm{D}$ celebrados entre competidores conllevan múltiples riesgos, el principal de ellos es el eventual comportamiento anticompetitivo que las partes de estos acuerdos pueden desarrollar. Dicho comportamiento encierra conductas como la creación de oligopolios, pactos desleales de exclusión y colusiones, las cuales se dan debido a que las partes del I+D abusan de la posibilidad que brinda esta figura de aliarse con competidores y buscan al utilizar este tipo de contrato acaparar una gran porción del mercado ${ }^{105}$.

Con el fin de evitar que los acuerdos de I+D sean utilizados para realizar conductas anticompetitivas la Unión Europea ha promulgado dos disposiciones. La primera de ellas es el Reglamento $316 / 2014$, "relativo a la aplicación del artículo 101, apartado 3 del tratado de funcionamiento de la Unión Europea a determinadas categorías de acuerdos de transferencia de tecnología" ${ }^{106}$. En dicha norma se han identificado dos tipos de cláusulas que pueden presentar problemas relacionados con la competencia. Las primeras son las denominadas "especialmente graves" o hardcore, las cuales, sin importar la cuota de mercado que posean las empresas parte, tendrán como efecto que no se aplique la totalidad del acuerdo. Las segundas son las cláusulas excluidas. En este tipo de cláusulas se tiene en cuenta el umbral de cuota de mercado de las empresas que suscriben el acuerdo poseen, si estas superan el umbral establecido en el reglamento y son parte de un acuerdo que incluye una cláusula cuyo contenido pueda considerarse un indicio de competencia desleal, se entiende que el acuerdo si tiene efectos, pero la cláusula no ${ }^{107}$.

La segunda norma (se aplica exclusivamente a los contratos I+D) es el Reglamento (UE) 316/2014 de la Comisión del 21 de marzo de 2014 relativo a la aplicación del artículo 101, apartado 3, del Tratado de Funcionamiento de la Unión Europea a determinadas categorías de acuerdos de transferencia de tecnología. Esta disposición señala los criterios que se tienen en cuenta para determinar cuándo un acuerdo I+D se considera contrario a la libre competencia ${ }^{108}$.

104 El Espectador. Confirmado: alianza Microsoft-Sony para competir en el mercado de videojuegos (en línea) (consultado el 17 mayo de 2019). Disponible en: https://www.elespectador. $\mathrm{com} /$ tecnologia/confirmado-alianza-microsoft-sony-para-competir-en-el-mercado-de-videojuegos-en-lineaarticulo-861124.

105 Tether, Bruce. Who co-operates for innovation, and why an empirical analysis. Op. cit., p. $947-967$.

106 Guerrero, Gaitán Manuel. El nuevo reglamento de transferencia de tecnología en la Unión Europea (en línea) (consultado el 18 de mayo del 2019). Disponible en: https:// propintel.uexternado.edu.co/en/el-nuevo-reglamento-de-transferencia-de-tecnologia-en-la-union-europea/.

107 Anderson, Mark. Technology transfer law practice and precedents. Op. cit., p. 4.

108 Por ejemplo, en las consideraciones de este reglamento se consagra que: Respecto de los acuerdos de transferencia de tecnología entre competidores, cabe presumir que cuando la cuota conjunta en los mercados de referencia correspondiente a las partes no sea superior al $20 \%$ y los acuerdos no contengan ciertas restricciones seriamente contrarias a la competencia, suelen dar lugar a una mejora de la producción o la distribución y reservan a los usuarios una participación equitativa en el beneficio resultante. 


\section{3. $I+D$ institucionales}

Son acuerdos I+D en los que una de las partes es una institución educativa, generalmente una universidad, o una institución dedicada a la investigación. La unión que resulta de este tipo de contratos puede ser universidad-universidad o universidadcompañía. La naturaleza de la unión universidad-universidad radica en que su objetivo principal es la mera cooperación académica, mientras que la unión universidadcompañía busca que el conocimiento generado en el ámbito de la academia sea utilizado para comercializar una tecnología ${ }^{109}$.

Ambas partes, tanto las universidades como las empresas, se benefician de dicho intercambio: las universidades obtienen apoyo financiero del sector privado, ganan experiencia ejecutando proyectos e investigaciones y aumentan las ofertas de empleo para estudiantes y profesores que deseen dedicarse a la academia. Y las empresas acceden a las infraestructuras de investigación y experiencia de la universidad, obtienen oportunidades de reclutar personal altamente calificado y se mantienen al día con las últimas tecnologías e investigación académica ${ }^{110}$, lo cual algunas veces puede llevar a que las partes celebren un spin off ${ }^{111}$.

Por ejemplo, desde el año 2007 hasta la actualidad Nokia y la Universidad de Cambridge han venido suscribiendo un acuerdo de $\mathrm{I}+\mathrm{D}$ que tiene por objeto adelantar una investigación conjunta sobre el impacto de la nanotecnología en el sector de las telecomunicaciones, la cual ha aportado múltiples avances científicos en esta materia ${ }^{112}$.

Sin embargo, debido a la confluencia de intereses opuestos albergados por las partes es posible que se genere tensión en la relación contractual, ya que, por un lado, las compañías realizan contratos de I+D exclusivamente con el fin de lograr cumplir sus metas de innovación a un menor costo, mientras que, por otro lado, las universidades no solo buscan el lucro o la reducción en costos de sus procesos

109 TIJSSEN, RoBERT. R\&D globalization processes and university-industry research cooperation: measurement and indicators (en línea). En: cwTs Centre for Science and Technology Studies (cwTs) Leiden University, 2012 (consultado el 23 de mayo de 2019), p. 4-5. Disponible en: https://openaccess.leidenuniv.nl/handle/1887/19352.

110 Hertzfeld, Henry et al. Intellectual property protection mechanisms in research partnerships. En: Research Policy, 2006, vol. 35, n. ${ }^{\circ}$ 6, p. 820. "Companies found great difficulty in dealing with the university technology transfer offices and officers. Although they cite variations in the levels of competence in these offices, they find them generally inexperienced in their position, hard to negotiate with, lacking in business knowledge, mired in time-consuming functions and lacking in authority to make a final commitment for the university."

111 Beraza Garmendia, José María, Rodríguez Castellanos, Arturo. Conceptualización de la spin-off universitaria revisión de la literatura. En: Economía Industrial, 2012, vol. 384, p. 143-152. "La bibliografía tradicional ha definido una spin-off como la iniciativa empresarial de un profesional que proviene de otra entidad. Más recientemente se ha afirmado que, además, debe tenerse en cuenta otro aspecto fundamental: la tecnología o el conocimiento que se generó en esa institución inicial y que se transmite a la spin-off a través de algún mecanismo".

112 Cambridge News. Joint research projects will initially centre on nanotechnologies. (En línea) (consultado el 20 de mayo del 2019). Disponible en: https:/www.cam.ac.uk/news/nokiaand-university-of-cambridge-to-partner-on-research. 
investigativos ${ }^{113}$ sino que también buscan salvaguardar valores como la libertad de investigación, libertad de cátedra, la autonomía universitaria entre otros ${ }^{114}$.

Ejemplos de lo anterior pueden ser: en primer lugar, la imposibilidad que generalmente tiene la universidad de publicar los resultados de las investigaciones conjuntas, toda vez que el contenido de dichas publicaciones muchas veces incluye información que podría poner en desventaja competitiva a la compañía partícipe de la investigación. En segundo lugar se encuentra el caso en el cual los investigadores cuentan con un estrecho margen para tomar decisiones que alteren el curso de la investigación, situación que supone un conflicto entre la libertad académica y autonomía que tiene el investigador en la universidad y la correcta administración de los intereses e información de la compañía.

Por último, es necesario mencionar que la tensión en las relaciones de una unión universidad-empresa también puede provenir de los diversos intereses políticos y económicos que conforman a una universidad, ya que existen casos en que dichas instituciones son financiadas por partidos políticos o grandes grupos de interés económicos, lo cual puede influir, por ejemplo, en la escogencia de las colaboraciones y proyectos de investigación que realiza ${ }^{115}$.

\section{CLASIFICACIÓN DE LAS INVESTIGACIONES}

Además de la clasificación presentada anteriormente, es menester mencionar que las investigaciones realizadas por medio de los contratos I+D pueden ser de tres tipos: la investigación básica, la cual está definida como aquel trabajo puramente teórico o experimental cuyo objetivo es adquirir conocimiento sobre el acontecimiento de un fenómeno mediante la observación del mismo, sin que lo anterior tenga una aplicación industrial especifica; la investigación aplicada, la cual tiene como objetivo adquirir nuevo conocimiento con el objetivo de aplicarlo para un fin desarrollado; finalmente, se encuentra el desarrollo experimental, que está enfocado en aquellos conocimientos que se adquieren con el fin de producir nuevos materiales, productos, dispositivos, procesos sistemas y servicios que mejoren sustancialmente aquellos ya existentes ${ }^{116}$.

113 Hertzfeld, Henry et al. Intellectual property protection mechanisms in research partnerships. En: Research Policy. Op. cit., p. 826. “The establishment of an R\&D with a university was reported to be the strongest and most deeply felt problem area for the surveyed companies in terms of IP protection. They all pointed to a growing trend in universities to be 'more aggressive' or 'greedy' in their negotiations with firms on IP issues for joint research."

114 Anderson, Mark. Technology transfer law practice and precedents. Op. cit., p. 6-10.

115 Ibíd.

116 Chorafakis, George. Public Financing of Research Taxonomy of public research-funding apparatuses. En Programme on Innovation, Higher Education and Research for Development, p. 9. "Stokes's classification scheme is compatible to that of a standard reference document in innovation there are three types of R\&D activities, basic research, applied research and experimental development. Basic research is defined as "experimental or theoretical work undertaken primarily to acquire new knowledge of the underlying foundation of phenomena and observable facts, without any particular application or use in view"; applied research as "original investigation undertaken in order to acquire new knowledge directed primarily towards a specific practical 
Según la Unión Europea, para el 2017 el 80\% de los acuerdos I+D celebrados en esta región están enfocados hacia el desarrollo de tecnologías ya definidas ${ }^{117}$ :

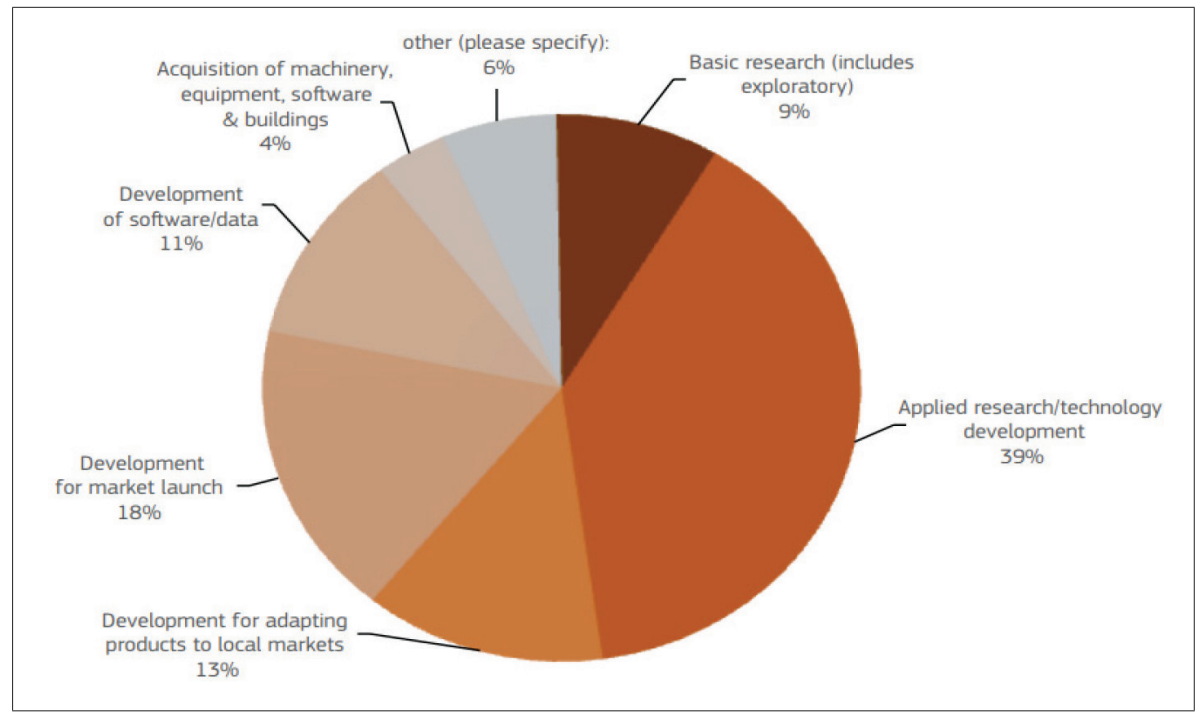

PROPORTION OF R\&D INVESTMENT BY TYPE OF INVESTMENT UNDERTAKEN. Note: The figure refers to 133 out of the 151 companies in the sample, weighted by $\mathrm{R} \& \mathrm{D}$ investment, representing $18.6 \%$ of the total $\mathrm{R} \& \mathrm{D}$ investment by the 1000 EU Scoreboard companies. Source: European Commission JRC-B (2017).

\section{ESTRUCTURA DEL I+D}

El I+D se caracteriza por su flexibilidad y capacidad de adaptación a las necesidades de las partes. Estas características permiten que el I+D se configure no solamente como un contrato, sino como un esquema negocial que comprende diversas figuras tanto precontractuales como contractuales. Lo cual tiene como consecuencia que la estructura y configuración contractual del I+D tenga un alto grado de complejidad $^{118}$. Con el fin de presentar las formas más comunes que adoptan los

aim or objective"; and experimental development as "systematic work drawing on existing knowledge gained from research and/or practical experience, which is directed to producing new materials, products or devices, to installing new processes, system [...]".

117 Potters, Lesley, Grassano, Nicola, Tuebre, Alexander. The 2017 European Union Survey on Industrial R\&D Investment Trends. En: Publications Office of the European Union, 2017, p. 27. ISBN: 978-92-79-76301-4.

118 Hertzfeld, Henry et al. Intellectual property protection mechanisms in research partnerships. En: Research Policy. Op. cit., p. 825. "Research partnerships are complex organizational arrangements. They take many forms ranging from infrastructures to support the informal sharing of information among partners to the creation of entirely new research entities. Some include large numbers of firms joining together to set industry standards. Others are truly one-on-one research ventures with specific technological goals. Still others are specific product-focused partnerships with either customers or suppliers aimed at solving a particular problem and thereby generating more business with just one other firm." 
acuerdos de $\mathrm{I}+\mathrm{D}$ se procederá a exponer las características de los I+D en las etapas precontractual y contractual.

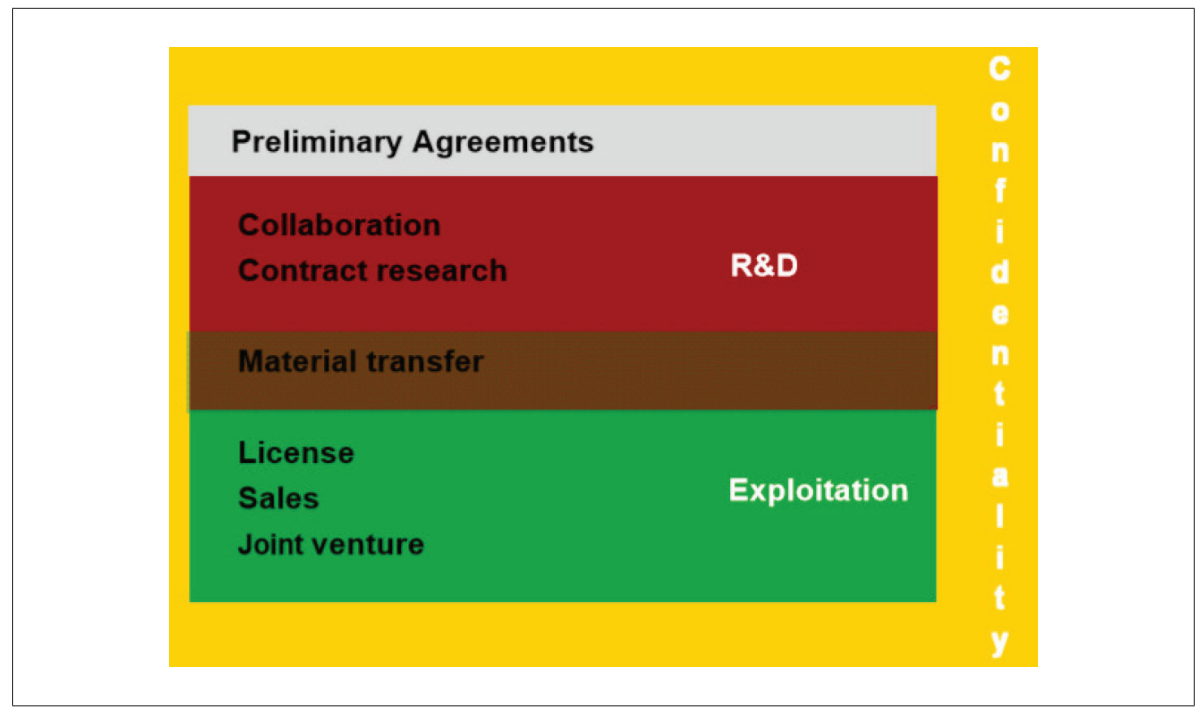

Pro Vendis. Overview -Agreements in R\&D and Technology Transfer. Brussels, 12 November 2010.

\section{A. I+D EN LA ETAPA PRECONTRACTUAL}

La etapa precontractual hace referencia al momento previo a la celebración del contrato, en el cual los individuos interesados en realizar un contrato negocian ${ }^{119}$ las condiciones de este. En esta fase las futuras partes suscriben documentos preparatorios ${ }^{120}$, cuyo propósito es plasmar lo discutido en las negociaciones, regular las negociaciones y algunas veces crear el compromiso provisional de realizar un contrato en el futuro ${ }^{121}$. El efecto jurídico de dichos documentos depende en gran mayoría de su redacción, pueden ser compromisos unilaterales o bilaterales y obligatorios para las partes conforme a lo estipulado por las partes.

En el caso de las alianzas de $\mathrm{I}+\mathrm{D}$ es común que debido a la complejidad ${ }^{122}$ y cuantía de las prestaciones que se pretenden pactar que las partes tomen la precaución

119 Bianca, Massimo. Derecho Civil ini. El contrato. Op. cit., p. 176. "[...] Las negociaciones son, precisamente, el contacto social que instauran las partes con miras a la posible celebración de un contrato. Estas negociaciones comprenden también la fase de formación de del negocio, pero pueden considerarse abiertas desde el momento de la invitación a ofrecer. En el sentido de que las negociaciones correspondan necesariamente a una fase anterior."

120 Hinestrosa, Fernando. Tratado de las Obligaciones ir. Negocio jurídico. Op. cit., p. 745.

121 Bianca, Massimo. Derecho Civil ini. El contrato. Op. cit., p. 202.

122 Tripsas, Mary, Schrader, Stephan, Sobrero, Maurizio. Discouraging opportunistic behavior in collaborative R \& D: A new role for government. En Research Policy, 1995, vol. 24, p. 369. "In addition, the difficulties in negotiating an acceptable agreement among partners increase rapidly with the number of participants. With two firms there is one relationship to 
de celebrar el contrato luego de haber establecido un iter formativo que comprende en la mayoría de dos figuras precontractuales:

La primera de ellas es la carta de intención o letter of intent ${ }^{123}$, un documento mediante el cual una persona procura precisarle a la otra su conducta futura en las negociaciones o su intención de emprender o continuar un proceso de negociación destinado a desembocar en la celebración de un contrato cuyo objeto, condiciones y modalidades están por determinar; precisamente se dice que, en principio, este documento unilateral no obliga a su autor y menos a su destinatario; pero en realidad todo depende de su redacción ${ }^{124}$.

La segunda es el memorandum of understanding o memorando de entendimiento, un acuerdo en el cual ambas partes de una negociación ponen de presente las expectativas, los principios y la ruta de la negociación para que se llegue a la firma de un contrato. El efecto jurídico de este tipo de figura precontractual es el mismo que el de las cartas de intención: depende de la redacción de las partes ${ }^{125}$.

\section{B. I+D EN LA ETAPA CONTRACTUAL}

En la etapa contractual la estructura del I+D se puede ver conformada por dos tipos de contratos: los contratos coligados y los contratos marco.

- Contratos coligados: El coligamiento contractual es aquella situación en la cual existen varios contratos vinculados ${ }^{126}$ entre sí por haber sido celebrados en cumplimiento de una operación económica global. Es decir, cuando subsiste entre ellos un nexo de interdependencia. Para determinar si los contratos son coligados se debe verificar la presencia de dos elementos: un elemento objetivo, esto es un nexo económico y teleológico entre los contratos, y un elemento subjetivo, que consiste no simplemente en la conciencia de los participantes en diversos negocios de tal nexo, sino además de un particular animus, y esto es en la intención de coordinar los diversos negocios hacia un propósito ${ }^{127}$.

En el caso del contrato de I+D es imperativo utilizar contratos coligados, toda vez que no es posible que el contenido prestacional de este tipo de acuerdos se agote

worry about, with three firms there are three relationships, with four firms, six relationships and so on. Getting a collaboration of many firms to agree can therefore be extremely difficult."

123 Furmston, Michel, Norisada, Takao. Contract formation and letter of intent. Primera edición, Estados Unidos: John Wiley \& Sons, 1998, p. 145. ISBn: 978-0471952381. "[...] A letter of intent is used to express the intention of the parties and does not constitute a binding agreement."

124 Hinestrosa, Fernando. Tratado de las Obligaciones ir. Negocio jurídico. Op. cit., p. 746. "Tales acuerdos preliminares que, aunque serios y aptos para generar confianza en la celebración del contrato no se consideran acuerdos que pueden vincular a las partes o pueden fundar una acción de daño contractual."

125 Ibíd.

126 Corte Suprema. Sala civil. Sentencia SC 18614 del 19 de diciembre de 2016, exp. 2008-00312-01, p. 30. "En el supuesto de varios contratos, ellos mantienen su tipicidad y autonomía, pero existe una finalidad 'supracontractual', un negocio que se quiere hacer y para el cual se utilizan varios tipos contractuales."

127 Morales Hervías Rómulo. Teoría General del contrato. Lima: Jurídica Grijley, 2000, p. 357. 
en un único contrato. Por ejemplo, para que las partes tengan un verdadero acceso a información técnica muchas veces es necesario licenciar dicho conocimiento ${ }^{128}$.

- Contratos marco: Los contratos marco son acuerdos que fijan en términos generales y abstractos la voluntad de las partes dejando su concreción a contratos posteriores ${ }^{129}$. Esto conlleva que este tipo de contratos sean muy flexibles y permitan que las partes vayan adecuando el contrato de acuerdo con las necesidades que surgen en la ejecución de este.

Es precisamente la flexibilidad de los acuerdos marco lo que permite en muchos casos que se pueda configurar un $\mathrm{I}+\mathrm{D}$, toda vez que muchas veces las partes desconocen el resultado que arrojará una investigación o un desarrollo de determinada tecnología. Luego las partes, gracias a los acuerdos marco, pueden establecer los criterios bajo los cuales se regirá la relación negocial.

\section{CONCLUSIONES}

La investigación conjunta es una alternativa elegida cada vez más por aquellos actores del mercado de la tecnología, ya que es una forma eficiente de afrontar los retos de la innovación.

Uno de los mecanismos por medio de los cuales se materializa dicha modalidad de investigación es el contrato de I+D el cual permite a las partes, por un lado, intercambiar y compartir derechos de propiedad intelectual, siendo esta la principal prestación, y, por otro, establecer un marco de cooperación en el cual cada individuo realiza un aporte en dinero o en especie con el fin de llevar acabo la actividad investigativa, a pesar de que los individuos no tengan la certeza de si los resultados de ella serán concluyentes o útiles.

Desde una perspectiva jurídica, el I+D está definido como un contrato consensual, bilateral, atípico e innominado. Esta última característica quiere decir entre otras cosas que el papel de la autonomía de la voluntad en la configuración del acuerdo es de gran importancia, ya que este no se encuentra regulado por el ordenamiento jurídico, lo cual significa que son los intereses de las partes y los principios generales del derecho de contratos los insumos a la hora de elaborar un contrato de esta clase.

Generalmente, los contratos I+D comportan cinco tipos de obligaciones:

128 T. K. DAs, A Resource-Based Theory of Strategic Alliances. Op. cit., p. 43. “Alliances are unilateral contract-based when they embody a well-defined transfer of property rights, such as the "technology for cash" exchange in licensing agreements. Licensing, distribution agreements, and R\&D contracts are the main forms of unilateral contract-based alliances. The key feature here is that individual firms carry out their obligations independently of others. Such contracts tend to be complete and specific, and partners are expected to perform on their own accordingly, without much coordination or collaboration. Thus, the level of integration is relatively low in unilateral contract-based alliances."

129 Bernal Fandiño, Mariana. Reflexiones sobre los contratos marco. En: Vniversitas, 2018, p. 1711 . 
En primer lugar, la obligación de realizar un aporte ya sea en especie o en dinero, lo cual hace referencia al deber que adquieren las partes de contribuir a la sostenibilidad económica de la investigación o del desarrollo tecnológico.

En segundo lugar, realizar una investigación conjunta implica que las partes deben desplegar todos aquellos comportamientos que materialicen el desarrollo y la ejecución de la investigación. Esta obligación usualmente se concreta en lo que se denomina coordination clauses, en las cuales se plasman los cronogramas de la investigación horas y monitoreo de aquella.

En tercer lugar, suministrar la información que sea necesaria para desarrollar la investigación, lo cual quiere decir que las partes deben poner a disposición del proyecto tecnológico que están desarrollando toda aquella información que permita llevar a cabo la investigación.

En cuarto lugar, ser diligente con el manejo de la información aportada por las partes que conforman el contrato, lo cual también comporta una carga de protección para quien aporta la información ya que esta debe estar protegida vía secreto empresarial, patente o el mecanismo pertinente.

La quinta y última obligación es establecer con claridad la distribución y el manejo que se les darán a los derechos de propiedad intelectual utilizados para la investigación y derivados de ella. Esta es tal vez la obligación más relevante del contrato, ya que en una investigación conjunta coexisten al tiempo múltiples derechos de propiedad intelectual, lo cual exige a las partes establecer la titularidad de cada derecho y el uso que se le dará en el marco de la relación contractual. Para ello es necesario que las partes identifiquen cuáles son los derechos ex ante, es decir, aquellos derechos que aportan los individuos para realizar la investigación y que generalmente se encuentran protegidos vía secreto empresarial o patente, y los derechos ex post, aquellos derechos que se generan como resultado de la investigación. Sobre estos últimos puede existir cotitularidad o la titularidad puede recaer en cabeza de una de las partes y aquella titular le permite el uso a la otra parte por medio de una licencia.

Finalmente, en lo que respecta a la tipología del contrato, este se divide en dos grandes grupos:

El I+D de financiación, en el cual una parte denominada researching party (en español, parte investigadora) se obliga a realizar un proyecto de investigación y desarrollo y otra parte denominada funding party (en español, financiador), que se obliga a suministrar una parte del capital necesario para costear los gastos de investigación y desarrollo y a apoyar de forma subsidiaria con información tecnología a la investigación. Lo que distingue a este $\mathrm{I}+\mathrm{D}$ de otros es el contenido y la extensión de la cooperación, toda vez que en este tipo de contratos la cooperación se enfoca principalmente en el aporte de información y la financiación que una de las partes hace a la investigación y desarrollo a la otra.

El I+D de cooperación está conformado por dos o más partes, quienes se obligan a cooperar con el fin de realizar un proyecto de investigación y desarrollo. Dicha cooperación se entiende en un sentido amplio, toda vez que son todas las partes 
quienes se encargan de la financiación del proyecto, de la dirección de la investigación, del desarrollo y de la distribución de derechos de propiedad intelectual en igual medida. Esta categoría se subdivide en tres:

- I+D verticales: Es el acuerdo que se da entre una compañía y aquellos sujetos que intervienen a lo largo del desarrollo de la cadena de valor de un producto, tales como proveedores (competidores indirectos). Ambas partes cooperan la una con la otra para participar en el desarrollo de investigaciones o tecnología con los objetivos de reducir costos de producción y expandir el mercado de un producto.

- I+D horizontales: Son contratos en los cuales dos partes que podrían ser competidores directos se colaboran mutuamente con el fin de desarrollar una investigación o una tecnología conjunta. Estos acuerdos tienen como objetivo, en primer lugar, enfrentar las problemáticas que afectan a un gremio o a los competidores de un sector determinado del mercado. Y, en segundo lugar, estos contratos buscan ampliar la base de mercado de las compañías. No obstante lo anterior, este tipo de acuerdos comportan el riesgo de ser un instrumento para que los individuos desplieguen conductas anticompetitivas.

- I+D institucionales: Son acuerdos en los que una de las partes es una institución educativa, generalmente una universidad, o una institución dedicada a la investigación. La unión que resulta de este tipo de contratos puede ser universidad-universidad o universidad-compañía. La naturaleza de la unión universidad-universidad radica en que su objetivo principal es la mera cooperación académica, mientras que la unión universidad-compañía busca que el conocimiento generado en el ámbito de la academia sea, eventualmente utilizado para comercializar una tecnología.

\section{REFERENCIAS}

Aceytuno, María-Teresa, Cáceres, F. Rafael, Los modelos europeos de transferencia de tecnología universidad-empresa. Revista de Economía Mundial [en línea] 2012 (sin mes) [fecha de consulta: 17 de mayo de 2019] pp. 2018. Disponible en: http://www.redalyc.org/articulo.oa?id=86625395009.

AdAm, Jaffe. Technological Opportunity and Spillovers of R\&D: Evidence from Firm's Patents, Profits and Market Value. The National Bureau of Economic Research. American Economic Review, vol. 76, n. ${ }^{\circ}$ 5. December 1986.

Anderson, Mark. Technology transfer law practice and precedents. Tottel Publishing. Second. Ministère de l'Éducation nationale. Ministere de l'ensseignement supérieur de la recherche. Guide pratique sur la gestión des contrats relarifs aux activités de recherche. Groupe de travail-Daf 2017.

Banco Internacional de Reconstrucción y Fomento/Banco Mundial. Conclusiones del informe del Banco Mundial titulado Perspectivas económicas mundiales 2008. 
Belderbos, Rene et al. Cooperative R\&D and firm performance. Elsevier Katholieke Universiteit Leuven, Faculty of Economics and Applied Economics, Naamsestraat 69, B-3000 Leuven, Belgium Universiteit Maastricht, The Netherlands.

Beraza Garmendia, José María y Arturo Rodríguez Castellanos, Universidad del País Vasco. Conceptualización de la spin-off universitaria, revisión de la literatura.

Bianca, Massimo. Derecho Civil. Tomo 3. El contrato. Universidad Externado de Colombia. 2000.

Buss, P., \& Peukert, C. (2015). R\&D outsourcing and intellectual property infringement. Research Policy.

Camacho López, María Elisa. Régimen jurídico aplicable a los contratos atípicos en la jurisprudencia colombiana. Revista Mercatoria, volumen 4, número 1 (2005).

Cambridge News. Joint research projects will initially centre on nanotechnologies. 2007. En línea https://www.cam.ac.uk/news/nokia-and-university-ofcambridge-to-partner-on-research.

Cantwell, John, D. Santangelo, Grazia. The frontier of international technology networks: sourcing abroad the most highly tacit capabilities. Information Economics and Policy 1999.

Casanova Navarro, Mariano. Proyectos de I+D e innovación en universidades: determinación de su carácter empresarial Universidad Politécnica de Valencia. Tesis doctoral.

Corte Suprema. Sala Civil. Sentencia SC 18614 del 19 de diciembre de 2016, exp. 2008-00312-01.

Das, T. K. A Resource-Based Theory of Strategic Alliances. Journal of Management 2000.

Alcácer, J., Chung, W., Location strategies and knowledge spillovers. Management Science 2007.

Delerue, Hélène et Lejeune, Albert. Joint Patenting in R\&d Alliances: Control Rights and Resource Attributes. Management 2013/2 (vol. 16).

Delerue, Hélène. Shadow of joint patents: Intellectual property rights sharing by SMEs in contractual R\&D alliances. Journal of Business Research 2018.

El Espectador. Confirmado: alianza Microsoft-Sony para competir en el mercado de videojuegos en línea. 17 de mayo 2019-6:12 am. Tomado de https:// www.elespectador.com/tecnologia/confirmado-alianza-microsoft-sony-paracompetir-en-el-mercado-de-videojuegos-en-linea-articulo-861124.

European Commission Joint Research Centre Directorate B Growth \& InNovation. The 2017 EU Survey on Industrial R\&D Investment Trends.

Fiori, Roberto. El problema del objeto del contrato en la tradición civil. Revista de Derecho Privado n. . 12-13, 2007.

Griliches, zVI (ed). R\&D, Patents, and Productivity. National Bureau of Economic Research. London. University of Chicago Press. 1987. 
Guerrero, Manuel. El nuevo reglamento de transferencia de tecnología en la Unión Europea. Innovation and Entrepreneurship. 22 May, 2014. Consultar https://propintel.uExternado.edu.co/en/el-nuevo-reglamento-de-transferenciade-tecnologia-en-la-union-europea/.

Guerrero Gaitán, Manuel. Los contratos de transferencia internacional de tecnología América Latina, Estados Unidos y la Unión Europea. Bogotá: Universidad Externado de Colombia, 2014.

Guerrero Gaitán, Manuel. 2009. Tipología de los contratos de transferencia de tecnología. Revista La Propiedad Inmaterial, n. ${ }^{\circ} 13$ (noviembre).

Hagedoorn, J. 'Organisational modes of inter-firm cooperation and technology transfer'. Technovation 1990.

Hertzfeld, Henry et al. Intellectual property protection mechanisms in research partnerships. Research Policy. 2006.

Hinestrosa, Fernando. Función, límites y cargas de la autonomía privada. Revista de Derecho Privado, n. ${ }^{\circ}$ 26, enero-junio de 2014.

Hinestrosa, Fernando. Tratado de las Obligaciones ir. Negocio jurídico, vol. I. Universidad Externado de Colombia. 2015.

Hoang, H. A., Rothaermel. How to manage alliences strategically. mit Sloan Management Review. 2016.

LutTERAL, PATRicio. La transferencia internacional de tecnología desafíos, tratamiento tributario internacional y propuestas para la redacción de contratos. Tesis de Maestría en Comercio Internacional. Universitat de Barcelona. Diciembre 2016.

Martínez-Pacheco, Belkys, Vargas-Chaves, Iván, Eduardo Salgado-FigueROA. El contrato de transferencia de tecnología: caracterización e importancia estratégica. Revista Brasilera de Direito Capes Qualis A1. Vol. 14. 2018.

Melich Orsini, José. Doctrina general del contrato, tercera edición. Editorial Jurídico Venezolana, Marcil Pons 1997.

Microsoft News Center. Sony and Microsoft to explore strategic partnership. May 16, 2019, https://news.microsoft.com/2019/05/16/sony-and-microsoftto-explore-strategic-partnership/.

Neme Villarreal, Martha Lucía. El principio de buena fe en materia contractual en el sistema jurídico colombiano. Revista de Derecho Privado n. ${ }^{\circ} 112006$.

Neme Villarreal, Martha Lucía. Carácter sinalagmático perfecto de los contratos unilaterales: una lectura a partir de la función de los contratos. Obligaciones, contratos, responsabilidad. Grupo para la Armonización del Derecho Privado Latinoamericano. Bogotá: Universidad Externado de Colombia, 2011. Memorias del encuentro del mismo nombre realizado en Bogotá en 2009.

Ospina Fernández, Guillermo, Ospina Acosta, Eduardo. Teoría general de los actos o negocios jurídicos. Editorial Temis Librería, Bogotá, 1980.

Payán Rodríguez, Carlos. 2011. Secreto empresarial, vigencia como mecanismo de protección en la propiedad intelectual. Revista La Propiedad Inmaterial, n. ${ }^{\circ} 15$ (noviembre). 
Patricio, Javier. Una historia del contrato en la jurisprudencia romana. Palermo: Salerno Arti Grafiche.

Pece, A. M. Simona, O. E. O. \& Salisteanu. Innovation and Economic Growth: An Empirical Analysis for CEE Countries. Procedia Economics and Finance. (2015).

Pérez García, Matías. Los elementos del contrato en la common law americano. Revista de Derecho Notarial Mexicano, Universidad Autónoma de México (UNAM) número 118. 2003.

Pino, Alberto. Una Aproximación continental al derecho inglés de los contratos. Una aproximación continental. Emhart University of Oxford. Julio 2014.

Pooley, James. El secreto comercial el otro derecho de P. I. OMPI Revista. Junio 2013.

Public Financing of Research Taxonomy of public research-funding apparatuses. Draft Report By author George ChORAFaKis.

Rajneesh, Narula, Hagedoorn, John. Innovating through strategic alliances: moving towards international partnerships and contractual agreements. Technovation. Volume 19, Issue 5, February 1999.

SÁnchez, Lorenzo Sixto. El Derecho inglés y los contratos internacionales. Tirant lo Blanch. 2013.

Sconamilio, Renato. Teoría general del contrato. Casa Editorial Dr. Francesco Vallard. 1961.

Sohn, So \& Mооуеов, Lee. "Conjoint analysis of R\&D contract agreements for industry-funded university research", The Journal of Technology Transfer, Springer, vol. 37(4). 2012.

Tecnología y conclusiones del informe del Banco Mundial titulado Perspectivas económicas mundiales 2008.

Tether, BRUCe. Who co-operates for innovation, and why. An empirical analysis. ESRC Centre for Research on Innovation and Competition (CRIC), University of Manchester and UMIST, Manchester M13 9QH, UK. Research Policy 31 (2002).

Tijssen, R. J. W. "R\&D globalization processes and university-industry research cooperation: measurement and indicators". CWTs Centre for Science and Technology Studies (CWTS) Leiden University (2012).

TRIPSAS, MARY et al. Discouraging opportunistic behavior in collaborative R \& D: A new role for government. Sloan School of Management, Massachusetts Institute of Technology, 50 Memorial Drive, Cambridge, MA 02139, usA Final version received November 1993.

Bernal Fandiño, Mariana. Reflexiones sobre los contratos marco. En: Vniversitas, 2018.

Unesco Institute for Statistics. How much does your country invest in R\&D. En línea http://uis.unesco.org/apps/visualisations/research-and-developmentspending/.

wIPPO Intellectual Property and R\&D: A Path to Success. En línea: https://www. wipo.int/ipadvantage/en/details.jsp?id=2559. 